\title{
AS SOCIEDADES NACIONAIS DA CRUZ VERMELHA DO JAPÃO E DA CHINA: FUNDAÇÃO E ATUAÇÃO NOS CONFLITOS REGIONAIS DE FINS DO SÉCULO XIX E INÍCIO DO XX
}

\author{
Victor Hugo Luna Peres ${ }^{1}$
}

\begin{abstract}
Resumo: Em fins do século XIX e no primeiro decênio do XX, o movimento humanitário internacional ganhou força e se difundiu ao redor do globo através de várias instituições promotoras de seu novo sistema de valores. Entre elas, papel de destaque coube ao Comitê Internacional da Cruz Vermelha e as Sociedades Nacionais que atuaram de forma significativa na prestação de socorro e auxílio humanitário em diversas partes do globo, tanto em situações de conflito quanto frente a desastres e calamidades naturais sofridas por populações civis. A participação no trabalho de ajuda humanitária desempenhado pelo Movimento da Cruz Vermelha foi rapidamente interpretada pela Comunidade Internacional como sinal distintivo de "Civilidade" e "Progresso" das nações e povos. Desta maneira, as classes dirigentes dos recém-forjados Estados nacionais e parte de suas elites apressaram-se em associar-se ao crescente movimento. No contexto do Extremo-Oriente, o Japão foi pioneiro na adesão à Convenção de Genebra e na fundação de sua Sociedade Nacional, seguido, anos depois, pelo Sião e pela China. O presente artigo procura analisar o processo de assinatura e ratificação aos "Tratados da Cruz Vermelha", as formas de organização e constituição de suas Sociedades Nacionais e os significados políticos nacionais e internacionais de seu engajamento no movimento. Ademais, procura apresentar as formas de atuação dessas organizações em dois importantes conflitos regionais, a saber: a Primeira Guerra Sino-Japonesa (1894-1895) e a Guerra Russo-Japonesa (1904-1905).
\end{abstract}

Palavras-chave: Sociedades Nacionais da Cruz Vermelha; Japão; China; Conflitos Regionais.

Abstract: At the late19th and early 20th century, the international humanitarian movement dispersed around the globe through various promoting institutions. Among them, the International Committee of the Red Cross and its National Societies played an important role. They have acted significantly in providing relief and humanitarian assistance in conflict situations and in the face of natural disasters and calamities suffered by civilian populations. Participation in humanitarian relief work carried out by the Red Cross Movement was quickly interpreted by the International Community as a hallmark of "Civility" and "Progress" of Nations. In this way, the ruling classes of the newly forged national states and part of their elites hastened to associate with the growing movement. In the Far East context, Japan pioneered the adherence to the Geneva Convention and the foundation of their National Society, followed years later by Siam and China. This article aims to analyze the process of signing and ratifying the "Red Cross Treaties", the forms of organization and constitution of their National Societies and the national and international political meanings of their engagement in the movement. In addition, it tries to present the forms of action of these organizations in two important regional conflicts, namely: First Sino-Japanese War (1894-1895) and Russo-Japanese War (1904-1905).

Keywords: National Red Cross Societies; Japan; China; Regional Conflicts.

Originário de um movimento das elites europeias de meados do século XIX, como aponta Frank Käser, ${ }^{2}$ o movimento humanitário internacional e suas instituições

\footnotetext{
${ }^{1}$ Mestre em História pela Universidade Federal de Pernambuco. Membro do Grupo de Estudos sobre História da Ásia (GESHA) e do Conselho Editorial da Revista Leste Vermelho de Estudos Críticos Asiáticos. Contato: Universidade Federal de Pernambuco, $\mathrm{CFCH}$, Dept. de História, 11. andar, Av. da Arquitetura, s/n, CEP: 50740-550, Cidade Universitária, Recife-PE, Brasil. E-mail: victorhperes@ hotmail.com.

${ }^{2}$ KÄSER, Frank. "A civilized nation: Japan and Red Cross, 1877-1900". European Review of History: Revue européenne d'histoire. 23:1-2, 2016, pp.16-32, p. 16. Nesse artigo, o autor apresenta uma versão crítica do processo de fundação da Sociedade Japonesa da Cruz Vermelha conectando-o à realidade japonesa do período, às necessidades e interesses em jogo e aos sistemas de valores e crenças em vigor.
} 
promotoras - com destaque aqui para o Comitê Internacional da Cruz Vermelha e as Sociedades Nacionais da Cruz e Crescente Vermelhos ${ }^{3}$ - espraiaram-se rapidamente ao redor do globo, à medida que foram incorporadas às pastas ministeriais dos Estadosnação como instrumento a serviço de seus desígnios. Distante da trajetória personalista - centrada nos homens - idealizada e teleológica das narrativas oficiais, esse movimento e suas instituições percorreram caminhos tortuosos e fortemente moldados e atrelados às vicissitudes das histórias dos Estados-nacionais. Foi respondendo às demandas e expectativas desses agentes que o movimento atingiria em menos de um século a influência e poder de atuação em escala global. ${ }^{4}$

Essa rápida difusão, assimilação e adaptação das instituições e do sistema de valores morais associados à Cruz Vermelha pelos estados e por suas populações, deve ser compreendida - apesar da pouca atenção dada pela opinião pública e pela academia - como parte importante da configuração explicita e específica de um fenômeno mais amplo da modernidade: a globalização. ${ }^{5}$ Como bem delineia a autora:

A emergência de uma sociedade nacional da Cruz Vermelha em um dado país e a inclusão dos estados nos tratados e convenções requeridos para o reconhecimento do Comitê Internacional da Cruz Vermelha, marca um passo crítico na expansão das redes, instituições e ideias globais assim como no desenvolvimento nacional e internacional do país. ${ }^{6}$

Ele procura fugir aos pressupostos das narrativas oficiais da instituição e das narrativas memorialistas, no mais das vezes, eurocêntricas, difusionistas e/ou centradas nas grandes figuras (masculinas).

3 "The problem of the red cross emblem is one which, given the continuing antagonisms between religions and ethnic groups [...], ought to be resolved as soon as possible. This problem arose during the RussoTurkish war of 1876-77 when Turkey gave up the use of the red cross emblem and opted instead to use a red crescent on a white ground. That the red cross emblem might be construed as having some religious significance was certainly contrary to what the founders of the Red Cross movement or the States party to the original Geneva Convention of 1864 had wished. However, the way Europeans viewed the application of international law in the mid-nineteenth century was greatly influenced by the division between the "Christian world" and the "non-Christian world", and the perception of that division was in those days inextricably linked to the concept of "civilized nations". Thus the accession to the Red Cross Convention by the Ottoman Empire, an entity whose origins were non-Christian and non-European, as well as the departure from uniformity that resulted from use of the different emblem, became an occasion for the West to develop new ideas on the application of international law. Indeed, the Red Cross Convention was meant to encompass as many nations as possible and to maintain certain universal standards. Despite being a non-Christian nation, Japan did not, as did Turkey and Persia, choose to adopt a new emblem to indicate its membership of the international Red Cross movement." KOSUGE, N. Margaret. "The "nonreligious' red cross emblem and Japan.” RICR Mars IRRC March, 2003, vol. 85 n.849, p. 75.

${ }^{4}$ Ibidem.

${ }^{5}$ REEVES, Caroline. "From Red Cross to Golden Arches: China, The Red Cross, and the Hague Peace Conference, 1899-1900.” BENTLEY, Jerry H.; Bridenthal, Renate; YANG, Anand A. Interactions. Transregional Perspectives on World History. Honolulu: University of Hawai'i Press, 2005, p. 65.

${ }^{6}$ Ibidem. 
No campo externo, a adesão aos "Tratados da Cruz Vermelha" e a subsequente constituição das Sociedades Nacionais por parte dos Estados-nação servia de sinal distintivo da "boa" intenção em participar do "Concerto das Nações", assim como, reflexo do grau de "Civilidade" e "Progresso" de seu povo.

Nos Estados, a participação no movimento e a instalação de suas instituições foram acolhidas, assimiladas e adaptadas pelas classes dirigentes e suas elites como instrumentos cruciais e meios de promover uma modernização dos costumes (filantropia e caridade), das táticas e técnicas da arte da guerra, das práticas médicas, da negociação e aplicação do direito internacional, bem como, um importante elemento de fomento da coesão nacional em torno de valores cívicos e humanitários.

Levadas pelos ventos da Modernização e do Progresso, ao modo ocidental, as instituições de ação humanitária e o movimento da Cruz Vermelha tiveram ampla cobertura e divulgação através da imprensa internacional e seus ideais e valores foram compartilhados por diplomatas, médicos, ${ }^{8}$ enfermeiros e missionários ao redor do globo, porta-vozes de primeira hora desse novo sistema de valores.

Desta maneira, vinte e três anos após a criação do Comitê Internacional $e$ Permanente de Socorro aos Militares Feridos (renomeado Comitê Internacional da Cruz Vermelha, CICV) na Suíça, esse movimento humanitário receberia um impulso significativo em sua expansão, com a adesão do Japão em 1886 à Convenção de Genebra $(1864)^{9}$ e a subsequente fundação de sua Sociedade Nacional de Socorro.

\footnotetext{
${ }^{7}$ No período aqui trabalhado, os critérios de civilidade sofriam profundas transformações, como expõe Reeves: "Solidarity based on Christianity and the commitment to Christianize, paramount in the eighteenth century, became less imperative with the secularization of Europe in the wake of industrialization, and other values took the Christianity's place as benchmarks of civilization. While still rooted in Christianity, secular Enlightenment values such as the rule of law and the supremacy of progress (including material prosperity) began supplanting earlier criteria in the nineteenth century." [...] "The equation between the existence of a national organization and the presence of civilization was popular in the late nineteenth." Idem, p. 68.

8 "...the supporters of this humanitarian idea were members of the upper class. Here as also there a major part was played by the medical profession, particularly by medical officers. For Japan it must be emphasized that these doctors had studied Western medicine and through their studies had a good command of English, French and German. This made it possible, in the first place, for this section to interact on a global level with persons in Europe. They possessed both the necessary prerequisites of education and the financial means as well as the means of communication and the necessary access and contact to governments and administrations." KÄSER, Frank. "A civilized nation: Japan and Red Cross, 1877-1900”. Op. cit., p. 20

9 "Convenção para a melhoria da sorte dos feridos e enfermos dos exércitos em campanha". Disponível em: 〈http://www.mpsp.mp.br/portal/page/portal/cao_civel/normativa_internacional/Sistema_ONU/DH.pdf> Acessado em 20/04/2018.
} 
Anos mais tarde, outras nações do Extremo-Oriente seguiram o exemplo japonês: em 1895, o Sião $^{10}$ e, em 1904, a China. Com a adesão desses países à Convenção de Genebra e a instauração de suas Sociedades Nacionais avançava o projeto "universal" de Henri Dunant ${ }^{11}$ para o Movimento da Cruz Vermelha. ${ }^{12}$

\section{O Comitê Internacional da Cruz Vermelha e as Sociedades Nacionais}

Independentes e diferentes do Comitê Internacional, as Sociedades Nacionais compunham e ainda compõem parte importante da rede global de ajuda humanitária. Componentes já previstos desde as idealizações de Dunant, as Sociedades Nacionais de Socorro, desenvolveram e continuam a desenvolver funções estratégicas na divisão internacional do trabalho humanitário. Como afirmou Jean Christophe Rufin, a criação das Sociedades Nacionais respondia dentro do projeto de Dunant ao duplo desejo de "estar presente em todos os países e aptas a assim intervir rapidamente, mas preservando sua independência e diferença da Cruz Vermelha Internacional."13

O Comitê Internacional da Cruz Vermelha ${ }^{14}$ desenvolvia, em posição de neutralidade, a função de formulador e árbitro do Direito Internacional Humanitário através das Convenções de Genebra. ${ }^{15}$ A lógica da instituição era e continua sendo:

Suíça e universal, neutra e lidando com Estados, poderosa, mas dependente da palavra dada: são essas as ambiguidades da Cruz

\footnotetext{
${ }^{10}$ A congênere do Sião (atual Tailândia) teve suas bases na Sociedade Unalome Vermelho criada em 1893 por ocasião da disputa Franco-Siamesa de territórios. Em 1895, segundo Henri Coursier, o Sião passou a tomar parte no Movimento da Cruz Vermelha ao aderir à Convenção de Genebra (1864) e adotar o símbolo da cruz vermelha como emblema. COURSIER, Henri. La Croix-Rouge Internationale. Paris: Presses Universitaires de France, 1959, p. 28. Mais informações sobre a Sociedade Tailandesa da Cruz Vermelha, consultar a sessão História do site oficial da instituição. Disponível em: $<$ https://english.redcross.or.th/node/47> Acessado em 23/03/2018.

11 "Henri Dunant est suisse; c'est un philanthrope, un esprit généreux qui rêve que de fraternité et de bonheur universel. Le voilà soudain devant l'horreur des champs de bataille de Solferino. Fini la fertilisation du Maghreb et autres doux rêves. Désormais, il va se donner une ambition nouvelle et suivre une direction radicalement différente. Ce qu'il veut, c'est faire partager l'expérience de Solferino et forcer les souverains à considérer la cruauté de la guerre. Il écrit Un souvenir de Solferino, et ce livre fait le tour des cours d'Europe. Henri Dunant vient d'inventer la Croix-Rouge." RUFIN, JeanChristophe. L'aventure humanitaire. Paris : Gallimard, 1994, p. 48.

12 "Pour venir au secours des victimes, il faut donc appartenir au même espace qu'eux: celui de l'humanité. Il faut être neutre, et on ne peut donc confier aux militaires cette chose trop sérieuse qu'est le soin aux blessés. Une organisation indépendante, respectée par chacun, préservée de toute tentation militaire ou partisane, doit en être l'instrument. Telle sera la Croix-Rouge." Idem, p. 49.

${ }^{13}$ Idem, p. 54.

14 "Celle-ci est composée exclusivement de citoyens helvétiques; elle est indépendante à l'égard des gouvernements, [...]. National par sa composition, international par son action, le comité fondateur de la Croix-Rouge Internationale préserve sa neutralité et la capacité d'intervenir auprès de chaque gouvernement." Idem, pp. 54-55.

${ }^{15}$ Série de tratados formulados pelo $\operatorname{CICV}(1864,1906,1929,1949)$ - sediado em Genebra - que estabelecem, junto com os protocolos adicionais, leis no campo do Direito Internacional Humanitário.
} 
Vermelha Internacional. Desde a sua criação, a Cruz Vermelha Internacional mobilizou-se para fazer os Estados assinarem uma convenção no intuito de proteger os feridos de guerra; este objetivo foi alcançado com a Convenção de Genebra de 1864. Graças a isso, a Cruz Vermelha definiu um espaço legal para a ajuda humanitária e espera que os países que assinaram a Convenção respeitem as cláusulas que ela contém. ${ }^{16}$

Nesse esquema, coube e ainda cabe às Sociedades Nacionais cumprirem com o trabalho de ajuda humanitária emergencial frente às vicissitudes dos Estados-nacionais - aos quais elas estão ligadas - tanto em tempos de guerra quanto de paz. Pontas de lança na resolução dos casos emergenciais de proteção à vida e na defesa da dignidade humana, elas interviriam localmente na prestação de serviços de primeiros socorros e auxílio médico a militares feridos e refugiados envolvidos em situação de conflito em terra - e no mar, a partir de 1899, com a Conferência de Paz de Haia ${ }^{17}$ e a segunda Convenção de Genebra, $1906^{18}$ - e às populações civis em casos de desastres, calamidades naturais, fomes e epidemias.

O espraiamento rápido das ideias, bem como das instituições, ao longo da segunda metade do século XIX e na primeira do século XX, pode ser mais bem compreendido na Figura I:

\footnotetext{
${ }^{16}$ RUFIN, Jean-Christophe. L'aventure humanitaire. Op. cit., p. 53.

${ }^{17}$ Como apresenta e analisa Caroline Reeves: "The First International Peace Conference at the Hague, convened by Russian tsar Nicholas II to discuss peace, provides an answer repeated at all successive peace conferences and still appropriated today. [...] Despite its failure to achieve many of its stated goals, the Hague Conference was an important and enduring success in the terms and structure of the discourse on warfare in the civilized world. The Hague conference helped establish the way state actors thought and talked about international arms reduction and peacekeeping efforts, and about war and its legality. This discourse is as pervasive and relevant today as it was at the turn of the twentieth century." Além disso, foi tratada, nesta conferência, a questão da adaptação da Convenção de 1864 para a guerra no mar. REEVES, Caroline. "From Red Cross to Golden Arches". Op. cit., p. 68.

18 "Convenção para a melhoria da sorte dos feridos, enfermos e náufragos das forças armadas no mar." Estendeu os princípios e as obrigações da primeira Convenção às forças navais. Disponível em: $<$ http://www.mpsp.mp.br/portal/page/portal/cao_civel/normativa_intermaciona//Sistema_ONU/DH.pdf $>$. Acessado em $20 / 04 / 2018$.
} 


\section{Figura $\mathrm{I}^{19} \mathrm{O}$ Mundo da Cruz Vermelha}

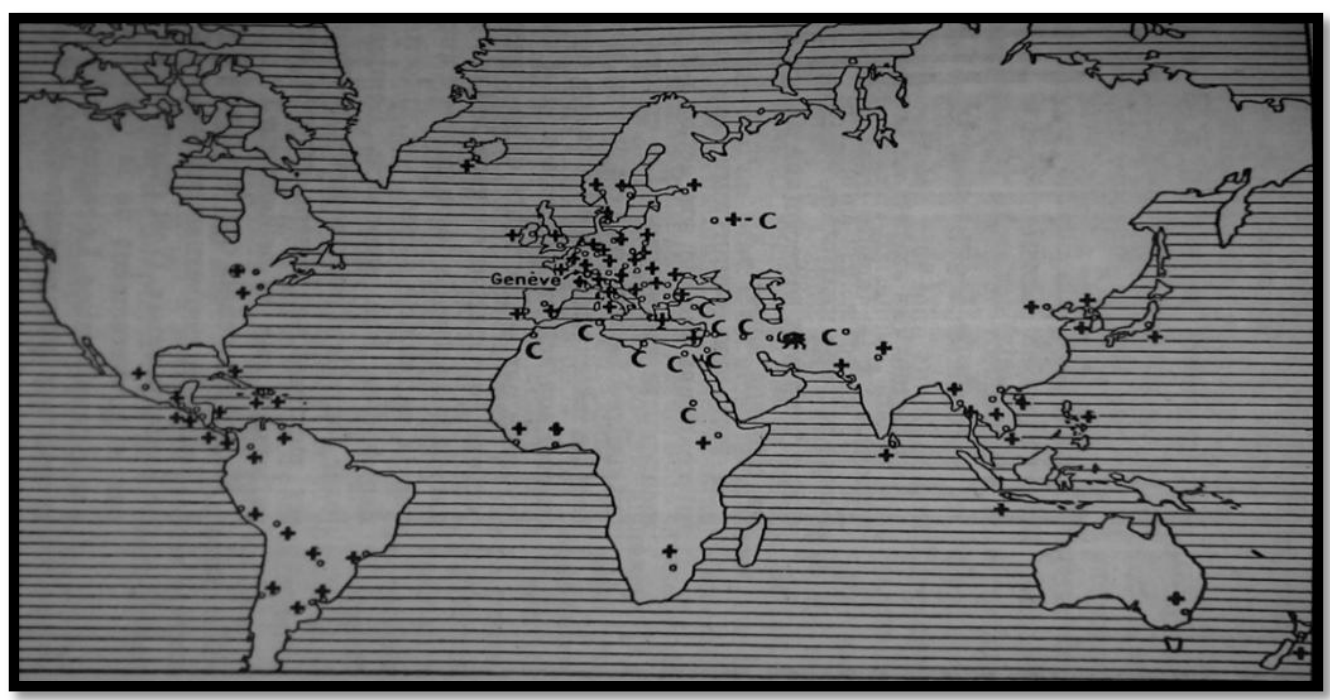

A Cruz Vermelha Internacional compreende o Comitê Internacional, a Liga e as Sociedades Nacionais reconhecidas, 1863-1957.

\section{A Ajuda Humanitária no Extremo-Oriente em fins do século XIX}

Para as nações do Extremo-Oriente, o século XIX representou um período difícil e de profundas transformações nos mais diversos campos. Uma urgente necessidade de reformulação das estruturas políticas, econômica e social se impôs, trazendo consigo um impulso de "modernização". Em resposta a ela, movimentos de reforma como os da Restauração (Criação) Meiji (明治維新 Meiji Ishin, 1868 - 1912) ${ }^{20}$ no Japão e o de Autofortalecimento (自強連動, Ziquiángyùndòng1861 - 1895) ${ }^{21}$ na China procuraram, através da adoção e adaptação seletiva de tecnologias, ideias e instituições ocidentais, vias de promover uma afirmação nacional e resistir às pressões imperialistas e suas desastrosas consequências.

\footnotetext{
${ }^{19}$ COURSIER, Henri. La Croix-Rouge Internationale. Op. cit., p. 56.

${ }^{20}$ Período de profundas reformas nas estruturas político-administrativa, econômica, cultural e tecnológica do Estado Japonês. Marcado pelos impulsos de modernização, adoção e adaptação das instituições, tecnologias, conhecimentos e modos de vida "ocidentais" à realidade nacional, com vistas ao fortalecimento do Estado-nacional.

${ }^{21}$ Numa visão positiva do movimento, Jonathan Spence aponta que: "Autofortalecimento, não fora um slogan vazio" [...], "os homens de Estado confucianos [...] sob a bandeira geral de restauração da ordem no Império Qing, [...] tinham conseguido criar novas estruturas para cuidar das relações exteriores $e$ coletar taxas alfandegárias, construir navios e armamentos modernos e começar a ensinar direito internacional e rudimentos de ciência moderna." Ainda segundo o autor, "chineses e manchus progressistas pareciam capazes de trabalhar juntos com o objetivo de preservar os aspectos mais estimados de suas culturas tradicionais ao adaptar seletivamente elementos do conhecimento e da tecnologia ocidentais às necessidades da China." Em Busca da China Moderna: quatro séculos de História. São Paulo: Companhia das Letras, 1995, p. 222.
} 
Através de configurações múltiplas e complexas, no mais das vezes ambivalentes e contraditórias, ambos os estados obtiveram resultados variados tanto na expectativa de fortalecimento nacional e "modernização", quanto nos demais setores onde tecnologias, técnicas e práticas externas foram aplicadas às realidades locais.

Ao mesmo tempo, desastres naturais como terremotos, secas, inundações e epidemias abatiam-se de maneira alarmante sobre suas populações, gerando profundos dramas sociais. ${ }^{22}$ Como resultado dessa nefasta equação, convulsões sociais e conflitos internos e externos - estouraram por todos os lados, produzindo um número incalculável de vítimas. Um rápido levantamento feito por Caroline Reeves a respeito da realidade chinesa dá a dimensão do desastre humanitário:

No início do século XX, as paisagens naturais e políticas da China estavam em confluência. Desastres naturais - inundações e secas, fome e outras catástrofes - ocorreram com uma frequência alarmante. Entre 1876 e 1879 , de nove a treze milhões de chineses morreram de fome induzida pela seca, e vinte anos depois, a China perderia mais meio milhão de pessoas em mais uma fome na China do Norte. Esta situação terrível foi exacerbada por episódios de violência civil, já que líderes da China e pessoas comuns experimentaram alternativas ao antigo sistema dinástico. A rebelião quase religiosa de Taiping (185065) deixou 20 a 30 milhões de mortos chineses na guerra civil mais letal da história. A agitação interna não parou por aí. Levantes religiosos políticos e econômicos - continuaram em toda a dividida China de $1911 .^{23}$

Nesse contexto, o socorro e a ajuda humanitária vinham sobretudo de sociedades de benevolência e de associações de ajuda mútua. Calcadas em pressupostos budistas e confucianos, eram tradicionais na China e prestavam ajudas pontuais como serviços de auxílio médico e de atendimento às necessidades dos mais pobres. ${ }^{24}$ Essas instituições atuavam em caráter e escala local/regional e eram encabeçadas, no mais das vezes, pela aristocracia local, proprietários de terra e membros da administração pública, que

\footnotetext{
${ }^{22}$ A respeito destes acontecimentos e dos dramas sóciais deles decorrentes, ver: DAVIS, Mike. Holocaustos Coloniais: clima, fome e imperialismo na formação do Terceiro Mundo. Rio de Janeiro: Record, 2002. Vale consultar também o estudo monográfico de Hugo Leonardo A. Santiago: Os Campos da Fome: Estudo sobre a Gestão da Seca no Mundo Rural pelo Estado Chinês entre 1876 e 1879. Defendido no Departamento de História da Universidade Federal de Pernambuco, 2016.

${ }^{23}$ REEVES, Caroline. "Developing the Humanitarian Image in the Late Nineteenth and Early TwentiethCentury China". Op. cit., p. 117.

${ }^{24}$ LI, Yannan. Red Cross Society in Imperial China, 1904-1912. The Center on Philanthropy at Indiana University, p. 3, 18. Ver neste sentido o trabalho de Katheryn Edgerton-Tarpley. "'Pictures to Draw Tears from Iron' The North China famine of 1876-1879." In: Visualizing Cultures. Massachusetts Institute of Technology, 2010. Disponível em: 〈http://visualizingcultures.mit.edu〉. Acessado em: 16/02/2018.
} 
"adotavam a filantropia para moldar sua visão pessoal de uma comunidade benevolente bem como para desenvolver um sistema de parentesco estendido." 25

Porém, desde meados do século XIX, tais formas de organização pareciam já não mais responder de maneira eficaz à soma das vicissitudes desses novos tempos. Desmanteladas, à medida que o Estado Qing ruía - por uma complexa gama de problemas internos e externos -, elas já não davam conta de resguardar as populações frente às grandes, múltiplas e sobrepostas calamidades naturais e humanas que sobrevinham. Não somente secas, inundações, fomes e epidemias punham em cheque as vidas humanas. O movimento crescente de forças militares - nacionais e estrangeiras no interior do território e em suas fronteiras, assim como, a adoção de armamentos modernos somou-se aos flagelos desse período, impedindo ou dificultando em muitos casos as tentativas de socorro e a eficácia dos tratamentos médicos então disponíveis.

Os novos desafios impuseram a mobilização não só de oficiais do governo bem como dos tradicionais agentes chineses de filantropia pela busca, adesão, adoção e adaptação às instituições e práticas "modernas" de ajuda humanitária. No período aqui abordado, um número crescente dessas ações contou com o esforço conjunto de nacionais e estrangeiros, com destaque para a participação de médicos e missionários, ${ }^{26}$ na tentativa de atenuar a precariedade então vivenciada pela população chinesa.

É nesse contexto, como demonstra Yannan (Lukia) Li, que ocorreu uma profunda transição das fórmulas e formas, bem como, das esferas e da escala de atuação das instituições de caridade e filantropia. ${ }^{27}$ A partir de então, as linhas de atuação elevaram-se à escala nacional. Seus agentes promotores passaram rapidamente a se ligar não só aos debates, como as próprias redes de ajuda humanitária internacionais, procurando alhures por novos modelos que dessem conta de sua realidade. Na China, muitos desses sujeitos voltaram sua atenção para as estruturas e movimentos da recémcriada Sociedade Japonesa da Cruz Vermelha, devido a sua rápida e bem-sucedida instalação, adaptação e atuação em contexto nacional.

\footnotetext{
25 Idem, p. 3.

${ }^{26}$ Como mostra John K. Fairbank: "By 1894 the newer Protestant mission effort supported over 1300 missionaries, mainly British and American, and maintained some 500 stations - each with a church, residences, street chapels, and usually a small school and possibly a hospital or dispensary - in about 350 different cities and towns. Yet they had made fewer than 60,000 Chinese Christian converts. [...] But the influence of mission schools and hospitals, of missionary ideals and activities in seeking out the common man, translating Western literature, initiating women's education, and assisting in ancient tasks of charity and famine relief, was considerable." FAIRBANK, John. K. The United States and China. Harvard University Press, 1983, p. 202.

${ }^{27}$ LI, Yannan. Red Cross Society in Imperial China, 1904-1912. Op. cit., p. 20.
} 
No Japão, por sua vez, apesar da situação ser menos dramática durante esse período, o quadro era ainda assim de profundas transformações e convulsões sociais - a exemplo da Revolta Satsuma em $1877^{28}$ - além de pontuado por catástrofes naturais, como a erupção do Monte Bandai em 1888. Tais ocorridos também mobilizaram os dirigentes da nação e parte da sociedade, particularmente de suas elites, para o desenvolvimento de instituições e formas de prestação de socorro e auxílio humanitário frente às necessidades deles derivadas.

Entretanto, como destaca Käser, no caso japonês, o movimento humanitário diferente do que ocorreu na Europa, mesmo tendo surgido da iniciativa de membros da elite, particularmente da nobreza kazoku $\left(\right.$ 鏃 $^{29}$ - encontrou dentro das estruturas do Estado-nação o suporte e os recursos necessários para a consolidação e aprimoramento de seu projeto institucional e de ação humanitária.

Inscrito no conjunto das amplas reformas institucionais adotadas a partir da Reforma (Criação) Meiji, o projeto de organização de uma instituição de auxílio humanitário foi elaborado com base em um modelo centralizador - mas com amplo e desejado espaço para as parcerias público-privadas - e com forte influência do recémelaborado "humanitarismo nacional" de origem ocidental. Essa influência, também se fazia sentir tanto no que dizia respeito ao sistema de gestão e financiamento delineado para a instituição, quanto nas práticas e conhecimentos médicos então empregados.

O projeto foi elaborado e posto em prática, apenas 11 anos após a abertura Japonesa, ${ }^{30}$ como parte do programa de fortalecimento nacional. A nova organização serviria três propósitos principais: 1 . a desejada e necessária ajuda humanitária; 2 . fins de propaganda nacional pelo seu caráter moderno e civilizado; 3. a criação, promoção e consolidação de laços de coesão social em torno de valores cívicos humanitários.

\footnotetext{
${ }^{28}$ Última das revoltas samurai, ela marcou o fim da classe e o surgimento do novo Exército Imperial.

29 "Kazoku, in Japan, the unified, crown-appointed aristocracy of the period 1869-1947, which replaced the feudal lords. The kazoku ("flower family") class was created in 1869 as part of the Westernizing reforms of the Meiji Restoration. In this class the old feudal lords (daimyo) and court nobles (kuge) were merged into one group and deprived of territorial privileges. In 1884 the kazoku was reorganized into a European-style peerage, with the ranks of prince, marquis, count, viscount, and baron. Membership was opened to those who performed distinguished public service." Disponível em: $\langle$ https://www.britannica.com/topic/kazoku>. Acessado em: 22/03/2018. Fazia parte desta classe, por exemplo, o Conde Sano Tsunetami, promotor de várias ações de filantropia e fundador da Hakuaisha e da Sociedade Japonesa da Cruz Vermelha.

30 "Datava de 1854 que o Comodoro americano Matthew C. Perry forçara os japoneses a acabar com seu isolamento e a reconhecer as realidades das relações internacionais e do comércio externo." SPENCE, Jonathan D. Em Busca da China Moderna. Op. cit., p. 225. Ver também: FAIRBANK, John. K.; REISCHAUER, Edwin O.; CRAIG, Albert M. East Asia: Tradition and Transformation. Boston: Houghton Mifflin Company, 1989.
} 
Adotando e adaptando de forma surpreendentemente rápida e pioneira métodos e práticas exitosas no que concernia a questão humanitária, o Japão tornou-se uma referência no campo. Prova disso, foi a criação de sua instituição de socorro, a Hakuaisha (博愛社), pelas mãos do conde Sano Tsunetami em $1877^{31} \mathrm{e}$, dez anos depois, a sua adesão às Convenções de Genebras, em 1886 e a fundação de sua Sociedade Nacional da Cruz Vermelha, em 1887, dotada de inovadora estrutura de organização.

\section{A Fundação da Sociedade Japonesa da Cruz Vermelha (SJCV)}

A Sociedade da Cruz Vermelha Japonesa, (日本赤十字社, NipponSekijūjisha/ NihonAkaisekkijuji), foi fundada também por iniciativa do conde Sano Tsunetami em 1887 e instaurada sobre as bases da Hakuaisha. A nova instituição contou com o imediato patrocínio da família imperial e com a participação ativa da Imperatriz Haruko (postumamente, denominada Shoken).

Com características peculiares e inovadoras, frente às demais congêneres da Cruz Vermelha, a SJCV teve, no modelo de organização militar, sua estrutura de funcionamento e gestão. Centralizada e sob controle do Ministério da Guerra, ela passou a cumprir um papel de instrumento suplementar da política de "Enriquecer o país, fortalecer o exército" (富国強兵 fukokukyohei) levada a cabo na Era Meiji. ${ }^{32}$

Contando com uma ampla gama de parcerias do setor privado e da sociedade civil em geral, tanto em termo de financiamento como de engajamento voluntário, a instituição pôde rapidamente viabilizar suas operações. Essa grande participação era fruto das medidas bem-sucedidas levadas a cabo pelo Estado para sua organização e estruturação institucional, como bem expôs Käser:

Já a partir de 1887, pré-condições foram criadas gradualmente para incorporar a Cruz Vermelha Japonesa socialmente também a nível regional. Por recomendação de Arisugawa no Miya Taruhito, os governadores das prefeituras foram obrigados, em virtude de seu ofício, a fundar as Sociedades da Cruz Vermelha em suas prefeituras e atuarem como presidentes. Ao mesmo tempo, também foram fundadas secções locais, presididas pelos respectivos prefeitos. As esposas dos presidentes assumiram tarefas nas seções femininas. Desta forma, até 1903/4, um total de 48 seções regionais surgiram. Considerando que o Japão tinha (e ainda tem) 47 prefeituras (43 prefeituras mais Tokyo-to, Kyoto e Osaka-fu e Hokkaidō), todos os distritos administrativos no território japonês, incluindo Taiwan, tinham suas seções regionais. ${ }^{33}$

\footnotetext{
${ }^{31}$ KÄSER, Frank. “A civilized nation: Japan and the Red Cross 1877-1900.” Op. cit., p. 22-23.

${ }^{32}$ FAIRBANK, John. K.; REISCHAUER, Edwin O.; CRAIG, Albert M. East Asia. Op. cit., p. 529.

${ }^{33}$ KÄSER, Frank. “A civilized nation: Japan and the Red Cross 1877-1900.” Op. cit., p. 26.
} 
Essa forma de organização e recrutamento foi acompanhada de um largo trabalho de publicidade e informação feito pelo seu fundador Sano e outros membros destacados da organização, a exemplo do oficial médico Ishiguro Tadanori (1845-1941). Nessa campanha, os conceitos norteadores, os valores e princípios basilares da instituição foram divulgados por conferências e palestras, proferidas em todo o território nacional, além de outros no exterior. ${ }^{34}$ Sem contar o uso dos veículos de impressa nacional e estrangeira. O objetivo explícito dessa campanha era promover um enraizamento da instituição e de seus valores no seio da sociedade japonesa.

$\mathrm{O}$ crescimento da instituição em número de membros no primeiro decênio de sua existência em solo japonês indica o sucesso da instituição e das medidas adotadas: entre 1890 e 1897 ela saiu de 23,569 para 455,638 membros associados, dobrando este último número e atingindo a marca de aproximadamente um milhão em $1904 .{ }^{35}$

Ariga $\mathrm{Nagao}^{36}$ avaliava de maneira positiva o resultado da instituição já em 1896, como "uma organização de todo o povo japonês, ao invés de grupos privados, operada por indivíduos com interesse cívico ou patriótico." Em sua visão, ela era “uma única entidade, sob gestão pública e abrangendo toda a nação, que do soberano acima a seus cidadãos abaixo compartilham um propósito comum, bem como direitos e capacidades comuns." ${ }^{37}$ Tais resultados tinham origem, segundo ele, no "[...] fato de que a liderança da Cruz Vermelha Japonesa conseguiu promover a causa nacional via questões humanitárias e em convencer seus membros que esse compromisso humanitário também beneficiou a nação e sua reputação no mundo."38

Alçada à condição de campeã nacional, a Sociedade Japonesa da Cruz Vermelha pôde contar com largos recursos financeiros governamentais, parcerias privadas bem como das doações individuais a nível nacional e internacional de seus membros e demais cidadãos. Tais recursos lhe permitiram, em poucos anos, tornar-se, nas palavras de Nagao, uma verdadeira "máquina de salvamento" 39 com uma significativa estrutura

\footnotetext{
${ }^{34}$ Idem, p. 24-26.

${ }^{35}$ Idem, p. 26.

36 Famoso jurista e historiador japonês, autoridade na Cruz Vermelha Japonesa. Publicou livros importantes como: La guerre sino-japonaise au point de vue du droit international (1896) e La Guerre Russo-Japoinaise 1904-1905 (Obra póstuma, 1947).

${ }^{37}$ KOSUGE, N. Margaret. “The 'non-religious' red cross emblem and Japan”. In: RICR Mars IRRC March. vol. 85, n.849, 2003, p. 80.

${ }^{38}$ Ibidem.

39 "How Japan in war time observes International Law”. New York Times, 19/06/1904.
} 
(elogiada interna e externamente) de hospitais fixos e de campanha, tendas, barracas, animais e amplos estoques de medicamentos e material hospitalar.

Neste sentido, a instituição era vista, antes de tudo, como um "veículo para servir a nação" não só no atendimento emergencial aos seus soldados como também na promoção das atividades de socorro e ajuda humanitária em sentido mais amplo. ${ }^{40}$ Assim, uma de suas primeiras atuações se deu no auxílio a populações civis por ocasião da erupção de Monte Bandai em 15/06/1888 (Figura II). Considerado o pior desastre vulcânico da história recente do Japão, a explosão e os fluxos piroclásticos deixaram 477 pessoas mortas e outra centena de feridos e desabrigados. ${ }^{41}$

Figura II Erupção do Monte Bandai, 1888 $^{42}$

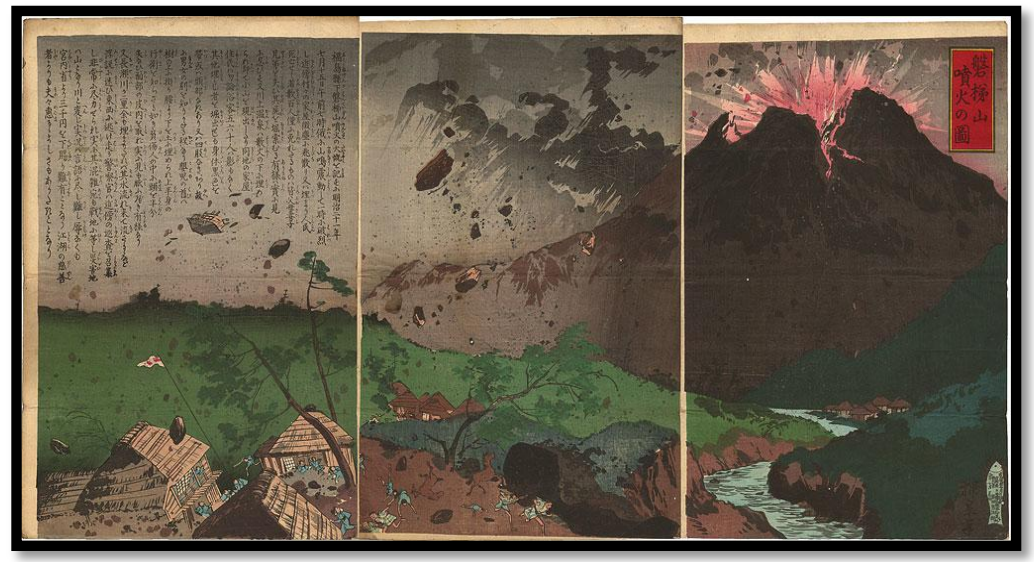

A atuação da SJCV durante os conflitos Sino-Japonês (1894-1895) e RussoJaponês (1904-1905) a promoveu a modelo de eficácia e sucesso na ajuda humanitária. A instituição desempenhou papel chave na preservação da vida de milhares de soldados e civis em situação de risco, inclusive chineses e russos. Esta atitude, conjuntamente com o respeito demonstrado por ela e seus membros aos valores humanitários e a sua estreita observância às regras do Direito Humanitário Internacional, tornaram-na um exemplo para outras congêneres ao redor do globo, inclusive para a China.

\footnotetext{
40 "Japan's Red Cross Society had its origin in the concepts of 'loyalty to the sovereign and patriotism' and was meant first and foremost as a "vehicle for serving the nation and giving succor to its soldiers." Idem, p. 78

${ }^{41}$ Ver descrição em: "The Japanese Eruption - Graphic Details. Villages Buried and Hundreds of Lives Lost.” New York Times, 07/09/1888.

${ }^{42}$ Tankei Inoue. Ukiyo-e retratando a Erupção do Monte Bandai em 1888. Disponível em: <https://en.wikipedia.org/wiki/Mount_Bandait/media/File:Tankei__Enuption_of_Mount_Bandai.jpg.> Acessado em: 20/03/2018.
} 


\section{A SJCV na Guerra Sino-Japonesa, 1894-1895}

A Primeira Guerra Sino-Japonesa foi uma expressão das tensões acumuladas na região desde aproximadamente $1876 .{ }^{43}$ De um lado da contenda, estava o Japão em processo acelerado de modernização e ascensão, ansioso por receber o reconhecimento de seu papel como potência regional e cumprir com o tenshoku, "o chamado divino". ${ }^{44}$ Do outro lado, a China Qing, antiga potência regional em evidente declínio, lutava em múltiplas frentes para manter a integridade nacional e a corte reinante. No meio estava a Coréia - estado tributário chinês - dividida internamente entre uma corte pró-chinesa e um crescente movimento nacionalista pró-Japão. Em 1894, uma série de levantes rebeldes (sobretudo de Tonghak ${ }^{45}$ ) coincidiram com a eclosão do conflito. ${ }^{46}$

O Japão protagonizou uma intervenção militar em território coreano e tomou o palácio em 21 de julho de 1894, designando um novo regente. Em resposta, a China enviou tropas em auxílio à corte, tanto por terra quanto por mar. Operando com precisão e empregando técnicas e armamentos modernos o exército japonês avançou rapidamente sobre a península, alcançando em outubro de 1894 o rio Yalu - marco de fronteira entre a Coréia e a Manchúria - e expulsando as forças chinesas do território coreano. No mês seguinte, os japoneses ocuparam os estratégicos portos de Port Arthur e Dairen (Ta-lien, em chinês) na península chinesa de Liaodong, impondo sérias derrotas às forças Qing. Rechaçada e constrangida com a perda de parte de sua reformada esquadra Beiyang ${ }^{47}$ nas Batalhas de Yalu (17/09/1894) (Figura III) e Weihaiwei (20/01 a 12/01/1895), a

\footnotetext{
${ }^{43}$ FAIRBANK, John. K.; REISCHAUER, Edwin O.; CRAIG, Albert M. East Asia. Op. cit., p. 553. As tensões começaram a crescer a partir deste período com a "anexação das Ryukyu, [podendo] a Coréia ter seguido o mesmo caminho na década de 1880, não fossem" os Acordos levados a cabo por Li Hongzhang com o rei coreano. SPENCE, Jonathan D. Em Busca da China Moderna. Op. cit., p. 225.

${ }^{44}$ ZIERER, Otto. Pequena história das grandes nações: Japão. São Paulo: Círculo do Livro S.A., 1976, p. 101. A respeito do termo tenshoku, John W. Dower aponta que: "In time, the Japanese coined the word tenshoku - literally "heaven's work" or "divine calling"- as their own code word for this expansionist vision." DOWER, John W. "Throwing Off Asia I". In: Visualizing Cultures, Massachusetts Institute of Technology, 2008, p. 16. Disponível em:< http://visualizingcultures.mit.edu > Acessado em: 16/02/2018.

${ }^{45}$ Tonghak era um movimento religioso popular com forte sentimento antiestrangeiro. FAIRBANK, John. K.; REISCHAUER, Edwin O.; CRAIG, Albert M. East Asia. Op.cit., p. 552.

${ }^{46}$ SPENCE, Jonathan D. Em Busca da China Moderna. Op. cit., p. 227.

47 "A major Chinese defense effort was to build a navy. [..] Li Hung-chang at Tientsin, as Northern Commissioner, created the principal fighting force, known as the Peiyang fleet. He contracted with foreign firms to build forts and bases in North China, including a naval base at Port Arthur and a fortified depot at Weihaiwei. Instead of building his own vessels as Foochow continued to do, Li bought from the big British and German arms firms. A British naval officer served as his chief adviser until 1890. By then Li's Peiyang fleet of some twenty-five vessels had nine modern warships." FAIRBANK, John. K.; REISCHAUER, Edwin O.; CRAIG, Albert M. East Asia. Op.cit., p. 622. Essa frota era formada, na época do conflito, por dois encouraçados, dez cruzadores e dois torpedeiros. SPENCE, Jonathan D. Em Busca da China Moderna. Op.cit., p. 228.
} 
China foi forçada à rendição e ao pedido de paz (Figuras IV e V). No mês de abril de 1895, foi formalizado o Tratado de Shimonoseki. ${ }^{48}$

\section{Figura III Batalha de Yalu ${ }^{49}$}

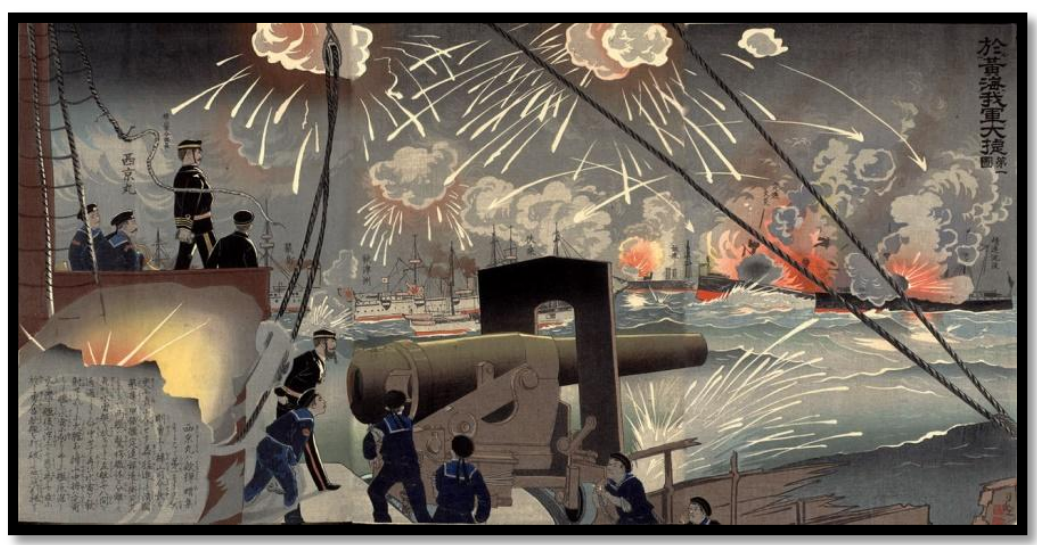

Figura IV Forças Navais Japonesas no Mar Amarelo Atirando e Afundando Navios de Guerra Chineses ${ }^{50}$

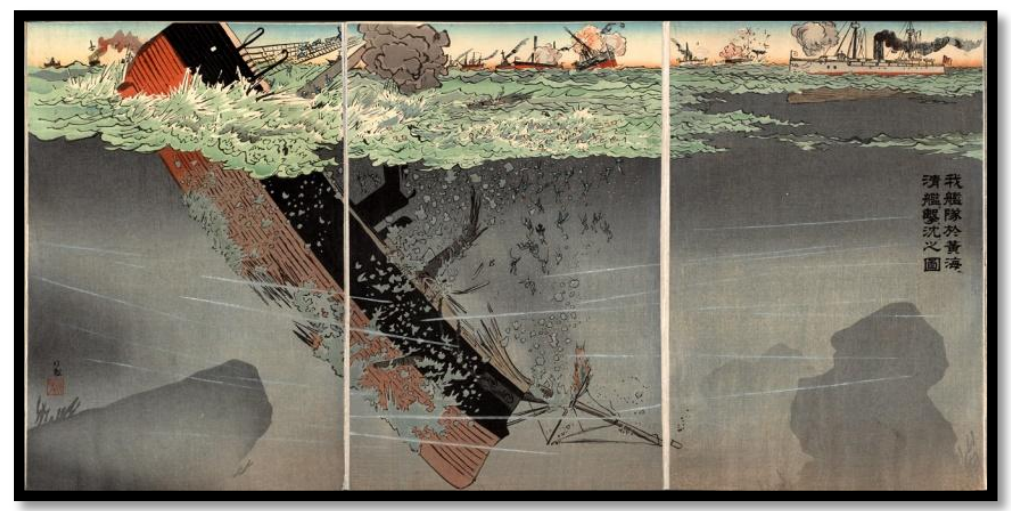

48 "Os termos do Tratado de Shimonoseki [...] eram desastrosos para a China. [...] ela teria de reconhecer 'a autonomia e independência total e completa da Coréia', o que, nas circunstâncias do momento, significava fazer da Coréia um protetorado japonês. Os Qing prometiam também pagar ao Japão 200 milhões de taéis de indenização de guerra, liberavam mais quatro portos e cediam ao Japão 'para sempre' toda Taiwan, as Pescadores e a região de Liaodong, no Sul da Manchúria. (...) Os protestos de russos, alemães e franceses forçaram os japoneses a desistir da reivindicação sobre Liaodong em troca de uma indenização adicional de 30 mil taéis, mas todas as outras cláusulas do tratado confirmadas." Ibidem.

49 Kobayashi Kiyochika. Batalha naval no Mar Amarelo (Rio Yalu), 1894. Disponível em: <https:/commons.wikimedia.org/wiki/File:Battle of the Yellow Sea by Korechika.jpg >. Acessado em: 20/03/2018.

${ }^{50}$ Kobayashi Kiyochika. Imagem de nossas forces navais atirando e afundando navios de Guerra chineses, outubro de 1894. Sharf Collection, Museum of Fine Arts, Boston. Disponível em: $<$ https:/ocw.mit.edu/ans7870/21f/21f.027/hrowing off asia 01/2000 38022 l.html $>$. Acessado em: 16/02/2018. 
Figura V Batalha de Weihaiwei ${ }^{51}$

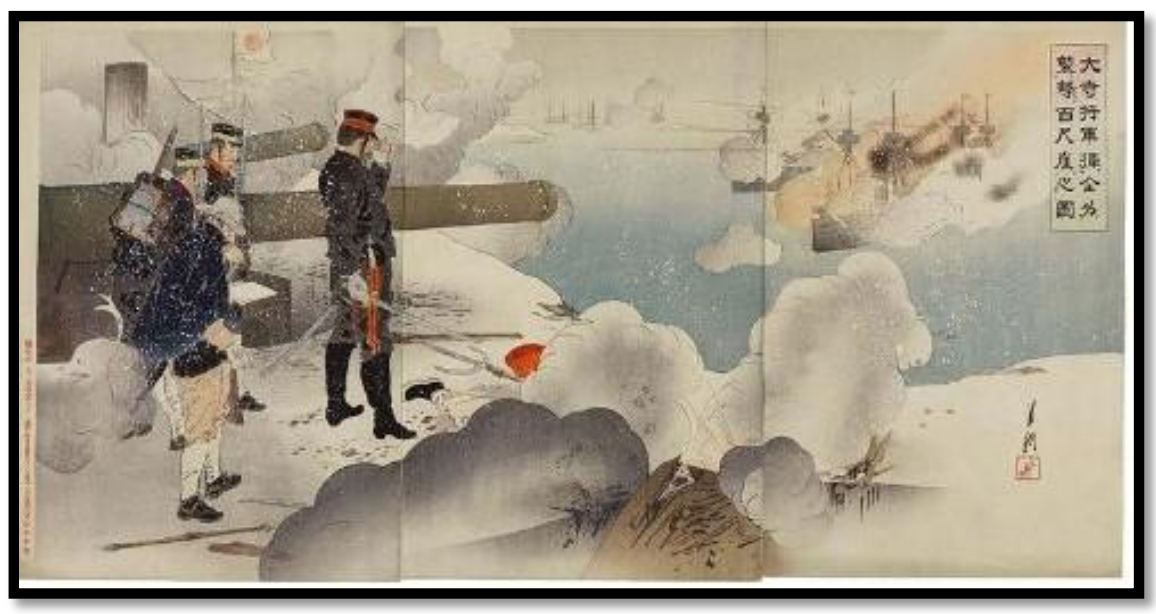

Ao longo do conflito, os japoneses promoveram uma verdadeira campanha midiática com vista ao reforço dos argumentos de guerra e à exaltação de suas qualidades potenciais condizentes com o almejado status de potência regional. Para tanto, o governo contou com serviços de comunicação e de imprensa eficazes que fizeram registros informativos do dia a dia do conflito e da bem-sucedida política de modernização das forças armadas, levadas a cabo na Era Meiji.

Com êxito, o jornalismo de guerra (propaganda) tornou-se o maior veículo de notícias em âmbito nacional do que ocorria na frente de batalha e forneceu imagens preciosas da atuação de homens e mulheres nos momentos mais dramáticos do conflito. Da mesma maneira, essas notícias e as imagens nelas inseridas também serviram a causa da propaganda nacional do governo japonês, exultando e promovendo um sentimento nacionalista de superioridade frente aos demais povos do Extremo-Oriente.

[A]s modernas xilogravuras para as quais voltamo-nos agora [são as fontes mais vividas] para recapturar um sentido emocional de apoio popular que acompanhou o surgimento do Japão como um poder agressivo, expansionista, no final do século XIX. Nacionalismo, militarismo, imperialismo, um novo senso de identidade cultural e mesmo racial - todos encontraram sua expressão mais extravagante aqui. Na verdade, as impressões populares não apenas 'capturaram' esse sentimento, elas desempenharam um papel de inflá-lo. Elas são a fonte mais dramática e facilmente acessível que temos para capturar a 'sensação' de redefinição da identidade nacional que acompanhou o début do Japão como uma grande potência. ${ }^{52}$

\footnotetext{
${ }^{51}$ Ogata Gekkō. Incidente na Batalha de Weihaiwei, 1895. Disponível em: $<$ https:/en.wikipedia.org/wiki/BattleofWeihaiwei\#/media/File:Ogata_Gekko_General Major_Odera Yasuzumi in the Battle of Wei haiwei.jpg.> Acessado em: 20/03/2018.

52 DOWER, John W. "Throwing Off Asia II". In: Visualizing Cultures, Massachusetts Institute of Technology, 2008, p. 4. Disponível em:< http://visualizingcultures.mit.edu>. Acessado em: 16/02/2018.
} 
Famosas à época, essas imagens/representações consolidaram-se como um gênero importante na imprensa japonesa. Estas xilogravuras foram produzidas por artistas como Kobayashi Kiyochika, Mizuno Toshikata, Ogata Gekkō, Watanabe Nobukazu: "3000 para menos de um ano de conflito". Nelas, esses artistas/repórteres procuravam passar não só as informações cotidianas do conflito, mas também construir um modelo de representação heroica e civilizada das modernas forças armadas japonesas - em seu estilo prussiano - destacando seu ímpeto e força de conquista. ${ }^{53}$

Espaço significativo foi dado também às imagens que retratassem os novos valores - particularmente cívicos e humanitários - promovidos então pelo Estado. Muitas delas “ foram destinadas a demonstrar a adesão do Japão 'civilizado' (para usar a linguagem do dia) às normas humanitárias, cuidando de maneira imparcial dos feridos de guerra de acordo com a Convenção de Genebra de 1864". ${ }^{54}$

Encarnado na SJCV, o espírito do movimento humanitário era apresentado através da atuação de médicos, auxiliares e enfermeiras nos campos de batalha, nos hospitais de campanha e em meio a procedimentos médicos de socorro emergencial (Figura VI). Em várias das xilogravuras, é possível ver com detalhes o atendimento ${ }^{55}$ dispensado aos combatentes - inclusive inimigos - e a destacada atuação feminina.

\section{Figura VI ${ }^{56}$ Enfermeiras da Cruz Vermelha Japonesa durante a Guerra Sino-Japonesa de 1894-1895}

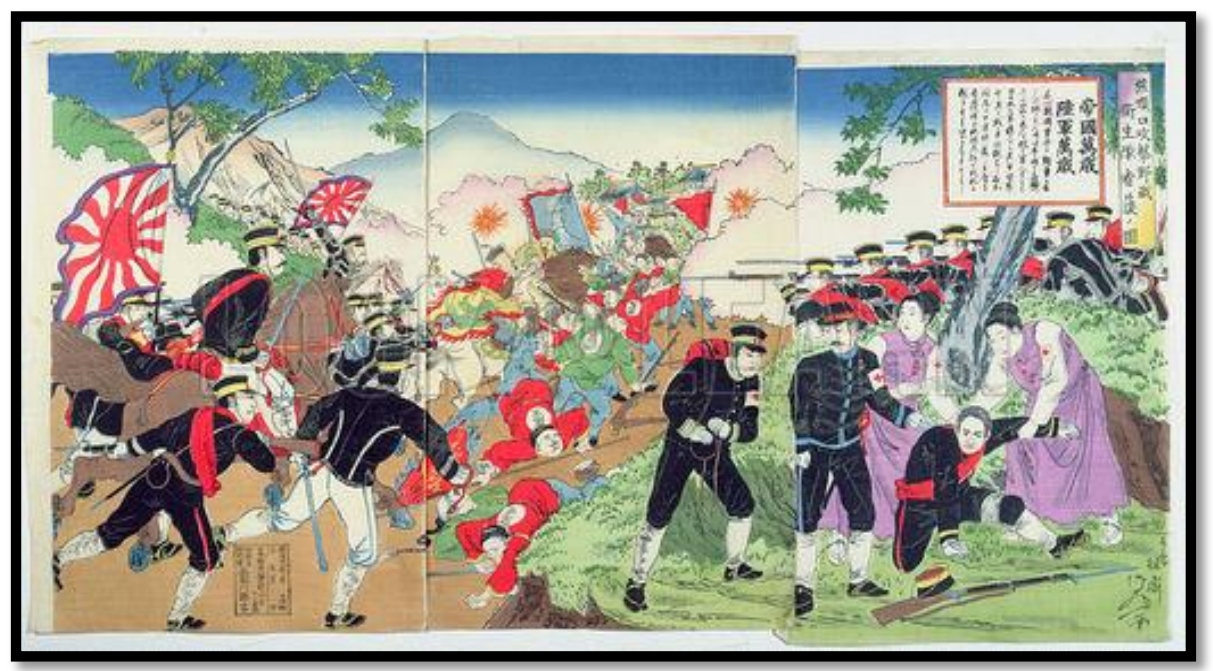

\footnotetext{
${ }^{53}$ Idem, p. 9-12.

${ }^{54}$ REEVES, Caroline. "Developing the Humanitarian Image". Op. cit., p. 120.

55 “... a estrutura posta a serviço do exército e da marinha japonesa para a guerra. Contava com um corpo de mais de 900 enfermeiras treinadas e um equipamento soberbo para o cuidado dos feridos." As enfermeiras, segundo o articulista, haviam sido treinadas por Dr. J. C. Berry, missionário americano que ensinou várias lições aos japoneses. "How Japan in war time observes International Law". New York Times, 19/06/1904.

${ }^{56}$ Disponível em: https:/www.allposters.comau/-sp/Nurses-from-the-Red-Cross-During-the-Sino-Japanese-War-of-1894-95posters i7680028 htm. Acessado em: 02/02/2018.
} 
A partir de uma análise mais ampla dos usos e funções das imagens no sentido humanitário, esse padrão de publicidade adotado no Japão vinha ao encontro de uma longa tradição, em vigor na Europa, de uso dos recursos visuais como instrumento de incitação à caridade e de mobilização filantrópica. Reeves bem expõe essas conexões:

O modelo do humanitarismo visual já estava difundido nos círculos humanitários internacionais. O sensacionalismo, a fetichização do sofrimento e a apresentação dos necessitados como vítimas sem poder estavam se tornando um modelo bem estabelecido na esfera humanitária euro-americana. Como no jornalismo impresso, onde o mantra do dia era "se sangra, é lido", o espetáculo do sofrimento parecia ser a maneira mais eficaz de levar o público ocidental-japonês à compaixão e a gerar fundos para causas dignas. ${ }^{57}$

Tais táticas, ao que parece geraram resultados importantes não só no sentido mobilização dos capitais necessários para financiamento da organização e de sua estrutura, como também, na mobilização e associação de novos membros a instituição. Como já comentado, nos anos seguintes ao conflito, o número de membros associados à instituição atingiria a incrível marca de um milhão. Número esse sem paralelo entre as demais congêneres da Cruz Vermelha ao redor do globo, a época.

Em mão oposta ao Japão, a China ainda não havia aderido à Convenção de Genebra e não possuía instituição de representação oficial na ação humanitária para tempos de guerra. ${ }^{58}$ As poucas iniciativas que foram encetadas partiram quase que exclusivamente de agentes estrangeiros e tiveram um alcance limitado, apesar de bastante significativo em termos de vidas humanas. Como aponta Li:

Em Yingkou, um grupo de médicos e missionários ocidentais estabeleceu um hospital de campo para assistir os feridos sob uma assinatura não oficial da Cruz Vermelha. O Comitê Internacional da Cruz Vermelha (CICV) também enviou remédios e doações para a China. Como a cirurgia de estilo ocidental tendia a ser mais eficaz do que os medicamentos chineses tradicionais para atender as feridas causadas por armas de fogo, o hospital da Cruz Vermelha atraiu muitos soldados feridos para serem tratados. Em quatro meses, outros três hospitais da Cruz Vermelha foram estabelecidos em Yingkou, admitindo mais de mil soldados chineses. ${ }^{59}$

Apesar desses esforços externos, levados a cabo no sentido humanitário, o conflito acabou por reforçar a imagem veiculada na imprensa internacional a respeito da

\footnotetext{
${ }^{57}$ REEVES, Caroline. "Developing the Humanitarian Image". Op. cit., p. 115.

58 Como aponta Li, a questão humanitária fui uma das lacunas deixadas pelo movimento de Autofortalecimento em curso na China durante a segunda metade do século XIX. LI, Yannan. Red Cross Society in Imperial China, 1904-1912. Op. cit., p. 24.

${ }^{59}$ Idem, p. 4.
} 
China como um país bárbaro, pouco preocupado com seus nacionais, com uma política e sentimentos pouco civilizados. ${ }^{60}$

Entretanto, membros da burocracia e das classes dominantes chinesas compreendessem a necessidade de juntar-se ao esforço humanitário internacional, particularmente no que concernia o socorro aos feridos de guerra. Apesar do flagrante mal-estar e dos inúmeros protestos contra o Tratado de Shimonoseki e suas consequências "humilhantes" para a China, foi o modelo institucional da Cruz Vermelha Japonesa - considerado viável e desejável - que inspirou vários dos reformadores sociais chineses. ${ }^{61}$

A compreensão da necessidade de instituições com este caráter em solo nacional levou à divulgação de várias das façanhas da SJCV e ao levantar de um clamor pela adoção e criação de instituição similar. Como bem aponta Li: "De maio de 1898 até abril de 1899, o Shenbao, jornal de grande circulação, publicou uma série de artigos para introduzir a história e os mecanismos da Sociedade da Cruz Vermelha, e advogoua como uma solução à emergência humanitária chinesa durante a guerra. ${ }^{962}$ Porém, a participação efetiva teria de esperar ainda mais alguns anos, antes de serem dados os passos concretos no sentido da adesão aos "Tratados Internacionais da Cruz Vermelha", bem como para a criação de sua sociedade nacional.

Apesar do desastre em termos de vidas humanas - as perdas chinesas atingiam 60.000, e apenas 1.400 para o Japão ${ }^{63}$ - o conflito serviu a causa da ampliação dos objetivos do movimento e sua consolidação legal. Por exemplo, algumas de suas

\footnotetext{
${ }^{60}$ Nessas mesmas xilogravuras produzidas a propósito da reportagem de guerra (propaganda) no Japão, pode-se claramente observar a aparição desse tipo de narrativa/representação de decadência e barbárie relacionada às forças do Império Qing (mas bem, poder-se-ia ampliar as concepções sobre o povo chinês de maneira geral). Ao analisar as imagens, por exemplo, percebe-se de forma destacada que, em boa parte delas, o uniforme e organizado exército japonês - em posição de superioridade - é posto em contraposição às vacilantes, desordenadas e aterrorizadas forças chinesas. A intencionalidade do contraste "quase maniqueísta" é clara e objetiva na atribuição dos significados, como se pode observa na ilustração V: organização x tumulto, civilidade x barbárie, moderno x retrógado, humanitarismo x desprezo com a vida humana. A esse respeito, ver mais em: DOWER, John W. "Throwing Off Asia II". Op. cit., p. 13.

${ }^{61}$ "Shimonoseki é o dobre de finados da restauração conservadora que adota empréstimos seletivos (as 'atividades à maneira ocidental').Os tradicionalistas criticam o custo e a ineficiência de um programa que não impediu a derrota. Os reformistas desejam uma mudança essencial, como no Japão, em nome de uma redefinição da 'essência' chinesa que dá lugar ao progresso e ao nacionalismo. A china dos anos 1980 oscila entre dois campos hostis." CHEVRIER, Yves. Mao e a Revolução Chinesa. Século XX. São Paulo: Ed. Ática, 1996, p. 29.

62 "From the May of 1898 to the April of 1899, o Shenbao, published a series of articles to introduce the history and mechanism of Red Cross society, and advocated it as a solution to China's humanitarian emergency during the war." LI, Yannan. Red Cross Society in Imperial China, 19041912. Op. cit., p. 4.

${ }^{63}$ DOWER, John W. "Throwing Off Asia II". Op. cit., p. 1.
} 
Batalhas como Yalu e Weihaiwei - e o seu custo em vidas humanas ${ }^{64}$ - serviram de ponto de partida para as discussões travadas internacionalmente em torno de conflitos navais que culminariam com as ampliações propostas na Primeira Conferência de Paz de Haia em 1899 e consolidadas na Convenção de Genebra de 1906.

\section{Fundação da Sociedade Internacional da Cruz Vermelha de Xangai (SICVX)}

Como visto acima, as circunstâncias chamavam a atenção de importantes segmentos da população chinesa para movimentos de natureza filantrópica e humanitária. As trágicas e dramáticas crises humanitárias em todo o território chinês e em suas bordas somavam-se dia após dia. Os antigos sistemas de benevolência e caridade governamentais e privados em escala local/regional não mais conseguiam atuar de maneira eficaz. Pior ainda era a situação no que dizia respeito às vicissitudes de sua população em territórios estrangeiros ou no que dizia respeito aos danos provocados por guerras e conflitos levados a cabo em suas fronteiras. ${ }^{65}$

Em fins do século XIX e nos primeiros anos do século XX, apesar da demora em transformar os padrões de caridade e os sistemas de ajuda locais, em sistemas mais amplos e modernos, iniciativas nesse sentido passaram a ganhar corpo nas discussões diplomáticas e em meio a grupos organizados da sociedade civil chinesa.

Os debates e arguições em favor da adoção de práticas modernas de filantropia passaram a somar-se, desde o fim da Guerra Sino-Japonesa, não só devido às difíceis situações vivenciadas por seus cidadãos, mas principalmente, em função das oportunidades de afirmação do Império Qing frente à comunidade internacional. ${ }^{66}$

Levados por essas expectativas, os diplomatas chineses desenvolveram discursos e manobras elaboradas no sentido de promover a adesão do país à Convenção de Genebra (1864) e ao movimento internacional humanitário durante a Primeira

\footnotetext{
${ }^{64}$ Os ataques a navios geraram perdas consideráveis. Por exemplo, logo no início do conflito, os japoneses afundaram um navio que transportava um contingente de 1200 homens das forças chineses que se dirigiam a Coréia, dos quais menos de 200 sobreviveram. Na batalha de Yalu, as perdas foram ainda maiores em ambos os lados. Entre os chineses, foram 850 marinheiros mortos e 500 feridos. Do lado japonês, só na capitânia Matsushima registrou-se mais de 100 ocorrências entre mortes ou feridos. Em Weihaiwei, os números voltariam a se repetir.

${ }^{65}$ Como aponta Li a respeito da região da Manchúria, palco dos eventos aqui expostos, por exemplo: "devastated by several modern wars [the regions] lacked the basic infrastructure and resource to satisfy the numerous demands for food and medicine, cross-regional cooperation was therefore not only necessary but imperative." LI, Yannan. Red Cross Society in Imperial China, 19041912. Op. cit., p. 18.

${ }^{66}$ REEVES, Caroline. "From Red Cross to Golden Arches". Op. cit., p. 84.
} 
Conferência de Paz de Haia em 1899. Como indica a autora, esses homens viam essas medidas como uma oportunidade de "em um dramático movimento empurrar a China da velha tradição de século de relações externas bilaterais para uma nova política de multilateralismo e internacionalismo como uma direção importante para o esforço de construção de um Estado chinês." ${ }^{67}$

No entanto, como Reeves ainda pontua, essas tentativas de traçar novos padrões e formas de participação do Estado chinês na comunidade internacional, a exemplo do que havia feito o Japão, não pôde ser levado a cabo.

Apesar das fortes recomendações de personalidads como Yang Ru e do Príncipe Qing (Yikuang) a frente do Zongli Yamen, a iniciativa viu-se frustrada frente ao entendimento contrário adotado pela corte e por uma ala conservadora (antiestrangeira) da burocracia ${ }^{68}$ Ela foi solapada pelas disputas políticas internas entre conservadores e reformadores - culminando com a repressão ao Movimento dos Cem Dias, $1898^{69}-\mathrm{e}$ pela Revolta dos Boxers, em 1900. ${ }^{70}$ Apesar do insucesso das tentativas de aderir à Convenção de Genebra, as recomendações neste sentido continuaram, vindas tanto de meios oficiais como de eminentes figuras da sociedade civil, a exemplo de Shen Dunghe, futuro idealizador da primeira sociedade nacional da Cruz Vermelha na China.

A iniciativa encetada por Shen Dunghe antecedeu a retomada dos tramites de ratificação dos documentos gestados em Haia e da própria Convenção de Genebra (1864). Conjuntamente com um grupo de comerciantes "patrióticos" de Xangai, ele organizou e fundou uma sociedade nacional de socorro de "caráter privado" durante os primeiros episódios de um novo conflito regional, a Guerra Russo-Japonesa $(08 / 02 / 1894-07 / 09 / 1895) .^{71}$

\footnotetext{
${ }^{67}$ Idem, p. 66.

${ }^{68}$ Idem, p. 84.

${ }^{69}$ Levado a cabo pelo imperador Guangxu, "entre junho e setembro de 1898, [foram divulgadas] "uma série extraordinária de éditos que merecia o nome de 'Reforma dos Cem Dias'.Embora a maioria dos éditos envolvesse propostas já levantadas pelos reformadores do autofortalecimento e pelos protestantes de 1895, jamais a iniciativa imperial apresentaria tal corpo coerente de ideias reformistas." Estas estavam baseadas nas ideias de pensadores como Kang Youwei e Liang Qichao, entre outros. No entanto, "muitos dos funcionários graduados, vendo com olhar deformado o programa de reformas de Guangxu, consideraram-no prejudicial ao futuro do país e destruidor dos verdadeiros valores intrínsecos da China." Sua tia, a imperatriz Cixi, através de um édito reassumiu o poder e afastou Guangxu - detendo-o no palácio. Ela mandou prender e assassinar seis dos assessores mais próximos do imperador, interrompendo o processo de reforma. Outros como Kang Youwei e Liang Qichao fugiram e exilaram-se no Japão. SPENCE, Jonathan D. Em busca da China Moderna. Op. cit., p. 233-234.

${ }^{70}$ Foi uma sociedade antiocidental e anticristã que lutava contra a presença estrangeira em solo chinês. Seus membros - chamados em chinês de "Punhos Harmoniosos e Justiceiros" - protagonizaram uma série de ataques contra cristãos (inclusive chineses cristianizados) e estrangeiros. Idem, p. 235-238.

${ }^{71}$ LI, Yannan. Red Cross Society in Imperial China, 1904-1912. Op. cit., p. 10.
} 
As bases do projeto eram fortemente influenciadas pelas formas de organização da congênere japonesa, vista como símbolo de eficiência e neutralidade. Ao lançarem o projeto da instituição em solo chinês, esses homens tinham a expectativa - assim como os diplomatas anteriormente - de alcançar em prol da nação os mesmos resultados conquistados pelos japoneses tanto na esfera interna quanto externa. Tais objetivos, como levantou Li ao analisar os documentos de fundação da nova instituição, eram bem próximos aos já delineados anos antes por Sun Gan, um dos primeiros incentivadores da iniciativa em solo chinês, a saber: "1. moralização do exército contando com tratamento médico adequado; 2. o ganho de reconhecimento dentro e fora da nação; 3. ter suporte médico em tempos de desastres internos; 4. aprimoramento da ciência médica chinesa". ${ }^{72}$

Com o propósito imediato de auxiliar a população chinesa da Manchúria presa em meio os conflitos da Guerra Russo-Japonesa, a Sociedade Beneficente da Cruz Vermelha da Manchúria foi fundada em 03 de março de 1904. A necessidade de respaldo e de reconhecimento internacional no intuito de levar a cabo seu plano de socorro aos seus concidadãos, haja vista, a postura hesitante e fraca do governo imperial, fez com que, sete dias após a inauguração, uma série de mudanças estratégicas fossem feitas na nova instituição. A título de exemplo, foram introduzidos representantes de nações ocidentais em seu conselho diretor, uma troca de nomenclatura e a alteração do idioma oficial da instituição para o inglês.

Em 10 de março, ela foi rebatizada como Sociedade Internacional da Cruz Vermelha de Xangai (SICVX). As alterações encetadas lograram os resultados esperados, como bem coloca Li:

“... o conselho internacional foi eficaz em apelar à intervenção internacional contra o bloqueio dos portos da Manchúria. Sob a proteção de convenções internacionais, a Sociedade da Cruz Vermelha conseguiu penetrar na zona de guerra, mesmo antes da assinatura oficial da primeira Convenção de Genebra, em 29 junho de 1904."73

Em abril, a instituição começava suas operações de socorro, apesar da postura oficial recalcitrante e da manutenção do discurso público de neutralidade adotado pelo

\footnotetext{
${ }^{72}$ Idem, p. 6. No que tange a questão da ciência médica, centenas de jovens - homens e mulheres chineses afluíram ao Japão em busca de formação médica ocidental, entre eles grandes figuras como Lu Xun. SPENCE, Jonathan D. Em Busca da China Moderna. Op. cit., p. 542-544. Ver também MOTTA, Bruno Pontes. "Destruir a Casa de Ferro": o escritor Lu Xun na China do Quatro de Maio, 19181927. Monografia. Bacharelado em História. UFPE, 2018.

${ }^{73}$ LI, Yannan. Red Cross Society in Imperial China, 1904-1912. Op. cit., p. 12.
} 
governo imperial, temeroso em provocar russos e japoneses. ${ }^{74}$ Contudo, como aponta Li, mesmo procurando maneiras de não se comprometer publicamente, o governo forneceu suporte à instituição de maneira indireta. ${ }^{75} \mathrm{E}$ esse apoio veio por meio da facilitação dos trâmites promovidos pelas autoridades centrais e locais, além do patrocínio de autoridades individuais, como a dos comissários Wu Zhongxi da Administração dos Telégrafos, Sheng Xuanhuai dos Correios e Comunicação - também dono da Empresa de Navegação e Comércio da China -, de Lu Haihuan dos Tratados Comerciais e das autoridades da Ferrovia Chinesa. Esses homens, usando de seus cargos e posições, procuraram viabilizar e ajudar no trânsito e nas comunicações de voluntários e refugiados, facilitando o acesso às novas tecnologias então disponíveis. ${ }^{76}$

Após a ratificação da Convenção de Genebra (junho de 1894), a instituição pode desenvolver suas ações de maneira eficaz tanto em solo nacional quanto fora dele, permitindo a seus membros cobertura legal e condições plenas de atuação, tanto nas frentes de batalha do conflito como bem depois dele.

\section{A SJCV E A SICVX na Guerra Russo-Japonesa, 1904-1905}

Marco de consolidação do Japão como uma potência, a disputa entre russos e japoneses por território da Manchúria e da Coréia e de portos estratégicos no mar Amarelo, degenerou em conflito. A Rússia procurava consolidar seus domínios na costa

\footnotetext{
${ }^{74}$ Idem, p. 13-14.

75 Idem, p. 12.

76 "The transformation towards national movement was also fueled by new technologies. Through the patronage of China Merchants' Steam Navigation Company, railway authorities and the Telegraph Administration, many of the communication and transportation services were offered free to the society. The railway, steamer and automobile allowed medical workers to transport the wounded to hospitals far away from the combat zone. The telegraph system facilitated the exchange of information for need and aids between the headquarter and branch offices in the front line. Meanwhile, local and national newspapers took the lead to educate the public about this new philanthropic concept, and supported the society through free media exposure of photographs, reports, and fundraising advertisements" Idem, p. 21. Reeves sublinha a importância dessas contribuições na viabilização dos serviços de socorro prestados pela instituição e no impacto das novas tecnologias nas atividades filantrópicas: "Thanks to donations from the Chinese Railway authorities and the Telegraph administration, elites from Shanghai were able to travel by train to the northeast and communicate by telegraph free of charge, facilitating relief efforts and drumming up local Chinese patronage. Magazines, newly emerging on the Chinese scene, published articles about Chinese Red Cross work. These new technologies helped spread the word about the Red Cross organization and improve its effectiveness across the country." REEVES, Caroline. "Developing the Humanitarian Image”. Op. cit., p. 120. Neste particular, o desenvolvimento das ferrovias teve papel facilitador e estratégico importante na mobilização do corpo de serviço da instituição ao longo do conflito. A respeito do desenvolvimento das ferrovias na China, ver o artigo de Renata C. Nobrega Santos e Christine Dabat: "A Civilização Acompanha as Locomotivas - A implementação da rede ferroviária no Brasil e na China, 1852-1912”. In: Revista Leste Vermelho - de estudos críticos asiáticos. Vol. 3 - n. 1, 2017, pp. 453-509.
} 
do Pacífico e avançava então sobre o território Qing da Manchúria e sobre a península coreana sem maiores resistências. Empreendimento de significativa monta e caro às ambições russas, a construção da linha férrea transiberiana cortava o território chinês da Manchúria até o porto russo de Vladivostok. ${ }^{77}$

Em mão oposta, o Japão ambicionava partes deste mesmo território continental, particularmente a península coreana, retirada de seu controle pelas negociações em Shimonoseki. Após uma série de manobras políticas, os japoneses conseguiram se liberar das imposições das potências estrangeiras sobre seu próprio território. Dispondo de forças armadas bem equipadas e treinadas, sentiram-se prontos para investir novamente sobre o continente e impor sua vontade a uma grande potência. ${ }^{78}$

O cerco a Port Arhur e a ocupação da península coreana marcaram o início, em fevereiro 1904, do conflito entre "o urso e o tubarão" ${ }^{79}$ A força naval russa na região foi imobilizada, bombardeada e afundada pelos japoneses que, sem resistência local, avançaram cortando novamente o território coreano até o rio Yalu e, em 1905, nos territórios da Manchúria. As forças russas foram expulsas do território chinês.

Da imponente esquadra russa sob comando do almirante Rojdestvenski, deslocada até a região através de circunavegação, poucos navios chegam a Vladivostok. A supremacia da novíssima esquadra japonesa (made in England) frustrou as pretensões russas no Estreito da Coréia $^{80}$ Com a vitória no Mar Amarelo, os japoneses conseguiram definitivamente a elevação de seu status internacional como potência.

Apesar disto, na Paz de Portsmouth (1905) definiu-se a nova posição do Japão que ganhou alguns prêmios de guerra, mas não todos. ${ }^{81}$ Mediado pelas potências ocidentais, o acordo garantiu ao Japão domínio apenas sobre a região de Port Arthur e áreas circunvizinhas - conquistadas pela segunda vez -, além da parte sul da Ilha de Sacalina. A Manchúria retornou à China, mas na condição de protetorado japonês. ${ }^{82} \mathrm{~A}$

\footnotetext{
77 "In 1896 Russia got Chinese permission to build the Chinese Eastern Railway 950 miles across Manchuria to Vladivostok, in order to avoid by this short-cut the costly tunnels and bridges which the trans-Siberian line would require on the 350-mile longer Amur route." FAIRBANK, John. K.; REISCHAUER, Edwin O.; CRAIG, Albert M. East Asia. Op. cit., p. 625.

${ }^{78}$ ZIERER, Otto. Pequena história das grandes nações. Op. cit., pp.102-103.

${ }^{79}$ Idem, p. 100.

${ }^{80}$ Idem, p. 104

${ }^{81}$ Ibidem.

${ }^{82}$ FAIRBANK, John. K.; REISCHAUER, Edwin O.; CRAIG, Albert M. East Asia. Op. cit., p. 556.
} 
estrada de ferro da Manchúria (Companhia das Estradas de Ferro do Sul da Manchúria), tornou-se um importante agente político japonês em solo chinês. ${ }^{83}$

Sob os olhos internacionais atentos, a guerra russo-japonesa tinha dois importantes significados para o Japão. Primeiro, era um palco para as forças militares japonesas exibirem evidências de 'civilização' - não só na força do Exército e da Marinha, mas também em suas eficientes organizações médicas militares, medicina avançada e capacidade para observar regras internacionais. ${ }^{84}$

E nesse sentido, mais uma vez, a SJCV serviu com maestria a causa nacional. A boa atuação da instituição durante o conflito foi garantida pelos largos investimentos feitos pelo governo japonês e por seus cidadãos tanto em solo nacional e como no estrangeiro. As solicitações de fundos para a causa da guerra, lançadas previamente pelo Governo do Japão, foram prontamente respondidas de todas as partes do mundo onde havia uma comunidade de origem japonesa (e mesmo de grupos de outras nacionalidades cujos concidadãos estavam envolvidos nos conflitos, como as comunidades chinesas nos E.U.A). O New York Times, por exemplo, publicava em suas edições de 10 e 13/02/1904, matérias anunciando a reunião dos cidadãos japoneses para o levantamento de fundos direcionados tanto para o empreendimento de Guerra, bem como, para o financiamento da sociedade nacional da Cruz Vermelha.

Contando, à época, com mais de um milhão de membros e uma estrutura moderna e bem equipada (Figuras VII e VIII), inclusive com dois novos navios hospitais - o Savior e o Mercy, recém-adquiridos $-{ }^{85}$ os japoneses puderam prestar um serviço humanitário aos feridos de guerra, em terra e no mar, à altura de suas pretensões como potência. Além de atender as complexidades médicas derivadas do considerável aumento no poder de fogo dos beligerantes devido aos novos tipos de armamento.

\footnotetext{
83 ZIERER, Otto. Pequena história das grandes nações. Op.cit., p.104; SPENCE, Jonathan D. Em Busca da China Moderna. Op. cit., p. 252.

${ }^{84}$ TAKAHASHI, Aya. The Development of the Japanese Nursing Profession: Adopting and Adapting. New York: Routledge Curzon, 2004, p.94.

85 "How Japan in war time observes International Law". New York Times, 19/06/1904.
} 
Figura VII ${ }^{86}$ Socorro aos Soldados Feridos, Guerra Russo-Japonesa

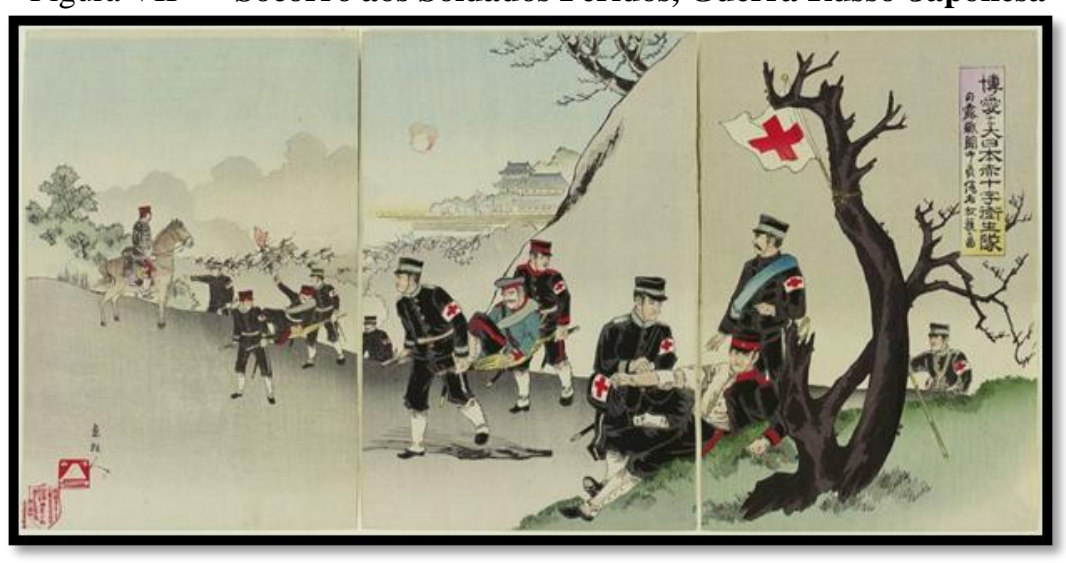

A rápida sofisticação do armamento japonês transformou a escala e a complexidade das formas de atendimento e tratamento. A necessidade de formação de quadros especializados em tratamentos específicos com a adoção de métodos ocidentais de medicina, e as implicações logísticas de atendimento a exércitos em escala moderna fizeram da instituição japonesa o elemento chave de ação humanitária bem como uma importante referência, não só no contexto asiático, mas em outras partes do globo, servindo de maneira notória a causa da propaganda nacional.

Apesar do uso propagandístico da instituição, o serviço de auxílio humanitário mostrou-se realmente eficaz e necessário. Neste sentido, os números são reveladores:

O grande número de vítimas da guerra russo-japonesa - oficialmente, 632.688 doentes ou feridos no lado japonês, e 77.809 presos russos doentes ou feridos - levou a sociedade a empregar mais de 5.000 pessoas, que foram divididas em 152 corpos. Isto foi em adição aos seus 1,27 milhões de membros. ${ }^{87}$

A resposta positiva a tão grandiosas demandas, como aponta Aya, devia-se, em boa medida, à estrutura criada pelos japoneses para o seu corpo médico:

As organizações médicas no Exército japonês foram colocadas em uma estrutura hierárquica, que controlava todas as unidades $\mathrm{e}$ operações médicas e providenciava atendimento integral aos militares. Cada operação médica estava conectada à outra para que os soldados feridos e doentes fossem enviados de volta para o próximo tratamento. Embora cada unidade estivesse sob um comandante militar regional, os oficiais médicos tinham autoridade sobre a gestão hospitalar e outros assuntos relacionados a condições sanitárias e médicas. Eles eram, portanto, parte do Exército regular, não inferiores ou

\footnotetext{
${ }^{86}$ Gakyō-jin. O Grande Corpo Humano da Cruz Vermelha Japonesa cuidando dos feridos durante a Guerra Russo-Japonesa, 1904.Disponível em: https://ocw.mitedu/ans7870/21f/21f.027/throwing off asia 01/gallery ppages 2000 541.htm. Acessado em 16/02/2018.

87 "The huge numbers of casualties from the Russo-Japanese war-officially 632,688 sick or wounded on the Japanese side and 77,809 sick or wounded Russian prisoners - led the society to employ more than 5,000 people, who were divided into 152 corps. This was in addition to its 1.27 million members." Informação retirada do site oficial do Shoken fund. Disponível em: <http://shokenfund.org/page5/>. Acessado em: 22/03/2018.
} 
estrangeiros na hierarquia militar. Os seus membros eram pessoal médico militar e as enfermeiras da SJCV empregadas em hospitais de reserva em casa, em hospitais de campo e em navios hospitalares foram colocadas sob os comandos de médicos. Assim, o pessoal do SJCV não trabalhou como voluntário civil, mas como pessoal médico militar provisório na guerra. [...] Todos os funcionários foram matriculados como médicos de reserva, boticários, enfermeiros e assim por diante, e eles tiveram que prestar juramento para se manterem prontos para um número fixo de anos para responder a qualquer momento ao chamado da sociedade para o serviço na guerra e outras calamidades. No caso das enfermeiras, estavam sob contrato por quinze anos, o que era o mais longo de todos. O pessoal do SJCV geralmente aceitou taxas de retenção durante o prazo de seus contratos. A este respeito, eles não eram voluntários, mas pessoal médico profissional reservado pela sociedade. ${ }^{88}$

\section{Figura VIII ${ }^{89}$}

\section{Guerra Russo-Japonesa: Grande Hospital de Batalha da Cruz Vermelha Japonesa}

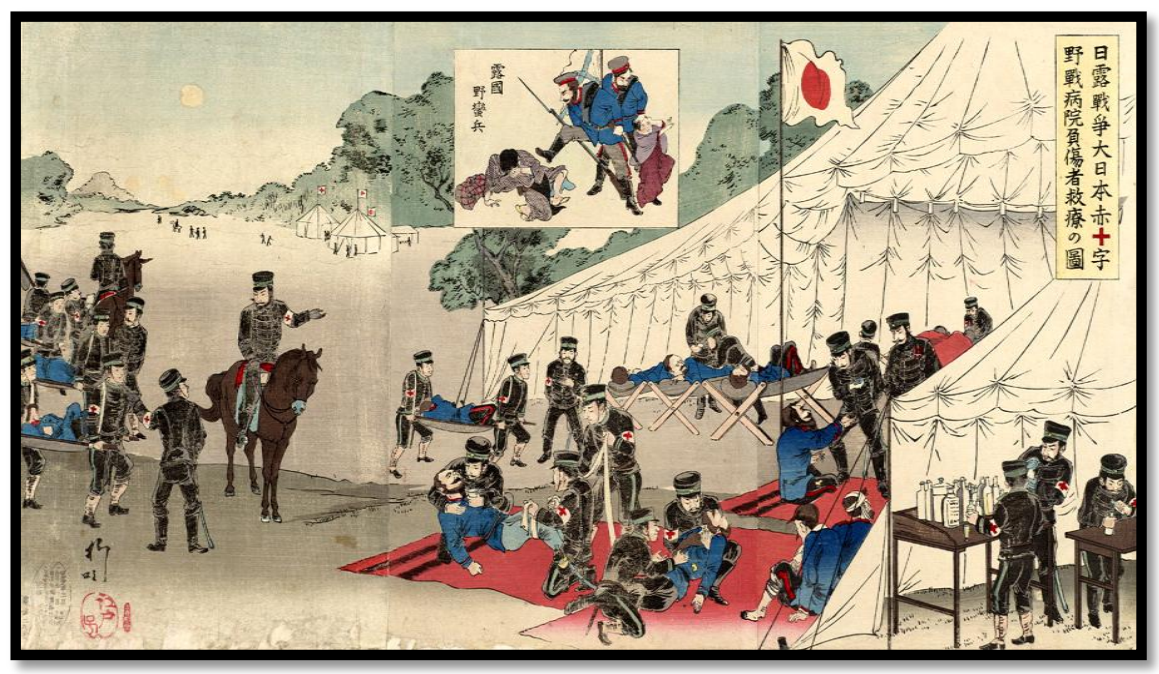

\footnotetext{
88 "The medical organizations in the Japanese Army were placed in a hierarchical structure, which controlled all medical units and operations and provided comprehensive treatment and care to servicemen. Each medical operation was connected to the other so that wounded and sick soldiers were promptly sent back to the rear for treatment. Although each unit was under a regional military commander, medical officers had authority over hospital management and other affairs relating to sanitary and medical conditions. They were, therefore, part of the regular Army, not inferiors or outsiders in the military hierarchy. Their orderlies were military medical personnel, and the JRC nurses employed at reserve hospitals at home, at field hospitals, and on hospital ships were all placed under the command of medical officers. Thus the JRC staff worked not as civilian volunteers but as professional military medical personnel in war. [...] All personnel were enrolled as reserve doctors, apothecaries, nurses, and so forth, and they had to take an oath to keep themselves ready for a mixed number of years to respond any time to the call of the society for service in the war and other calamities." TAKAHASHI, Aya. The Development of the Japanese Nursing Profession: Adopting and Adapting. Op. cit., p. 98.

${ }^{89}$ Utagawa Kokunimasa. Guerra Russo-Japonesa: Hospital de Campo de Batalha da Grande Cruz Vermelha Japonesa Tratando Feridos (na parte superior, detalhe mostrando os maus tratos cometidos pelos russos aos povos asiáticos), 1904. Disponível em: https:/ocw.mit.edu/ans7870/21f/21f.027/hrowing_off_asia 01/2000 367 l.html. Acessado em: 16/02/2018.
} 
A impressionante estrutura então desenvolvida chamou atenção em todo o globo. Figuras eminentes da área médica e da ação humanitária, assim como, a opinião pública internacional - informada através da imprensa - vislumbraram na sociedade japonesa um modelo a ser seguido e procuraram conhecê-la. ${ }^{90}$ Ainda no calor do conflito, em matéria de 07/11/1904, um correspondente estrangeiro do NYT em Tóquio fazia uma descrição bastante elogiosa das excelentes condições das instalações e do tratamento dedicado aos pacientes - nacionais e estrangeiros - no Hospital da Cruz Vermelha.

No ano seguinte, outros pareceres positivos vieram a público, como o feito por Miss Ethel McCaul, enfermeira britânica e autora do livro "Hospitais e Arranjos Sanitários", quando de sua visita de inspeção as instalações da SJCV. No relato publicado no NYT, em 18 de março de 1905, era apresentado ao público americano "o maravilhoso progresso que o Japão tinha feito no cuidado dos doentes e feridos" (Figura IX). ${ }^{91}$ Ela elogiava, principalmente, o bom tratamento dispensado pela Cruz Vermelha japonesa aos prisioneiros de guerra e aos feridos do exército russo, o que refletia "a humanidade e o bom senso comum" do corpo médico. ${ }^{92}$

Ademais ressaltava, em seu parecer, o rigoroso padrão sanitário e a participação feminina nas ações da instituição.

No Hospital da Cruz Vermelha, os compromissos ultrapassaram em muitos aspectos os padrões europeus. Tudo era limpo e razoável. Havia uma escola de treinamento de enfermeiras, onde a costura foi ensinada. Ali estava uma nação preparada para fornecer, 3.000 enfermeiras de exército totalmente treinadas e, prontas para fornecer todas as bandagens necessárias para trabalhos civis ou militares, todas feitas à mão. ${ }^{93}$

O correspondente internacional do NYT informava que mulheres atuaram não só no campo do atendimento como enfermeiras profissionais dentro das instalações médico-militares $^{94}$ mas, também, como voluntárias nas linhas de produção e

\footnotetext{
${ }^{90}$ Idem, p. 93

91 "Red Cross in Japan. Miss Ethel McCaul's book about Hospitals and Sanitary Arrangements". New York Times, 18/03/1905.

92 "There were many wounded Russians, and the lady was impressed 'by the medical officers' kind manners toward them." Idem.

93 Idem.

94 Diferente das demais formas de contratação, as enfermeiras tinham formas excepcionais, como bem explica Aya: "Although their services were non-voluntary, they did not receive any fees as reserves because, according to the society: they had received expensive training and because they were considered able to find ample remunerative employment as nurses when not serving with the society. The JRC nurses had, however, benefits that other ordinary nurses rarely enjoyed. They were entitled to receive special provisions for pensions or gratuities in case of invaliding, good service, or death. In addition, they
} 
abastecimento de materiais de primeiros socorros e demais gêneros de necessidade. Ainda nessa matéria, ele ressaltava o compromisso, desprendimento e zelo com que essas mulheres trabalhavam, dando a dimensão e a escala de seus afazeres:

Algumas palavras devem ser ditas em relação a um ramo da Sociedade da Cruz Vermelha chamada 'Associação de Enfermeiras Femininas Voluntárias'. Milhares de bandagens foram enroladas por essas ajudantes dispostas, que se encontram cinco vezes por semana em uma grande sala no hospital. Princesas, nobres, senhoras japonesas e estrangeiras dão o seu tempo em dias determinados e, às vezes, trabalham por oito horas consecutivas. Em menos de dois meses, 30.000 ataduras foram despachadas para frente [de batalha], cada uma tendo sido esterilizada e examinada, não sendo permitida a passagem de uma malfeita. Atualmente, milhares de pequenas porções estão sendo acondicionadas, contendo curativos de campo para cada soldado ter em seu bolso. [...] Nada é deixado ao acaso, e como cada artigo é feito de acordo com as diretrizes escritas, é perfeito. ${ }^{95}$

"Nada era deixado ao acaso". A estrutura, organização, eficácia, segurança e os cuidados - humanizados - eram tidos como pontos altos da instituição entre seus observadores e comentadores. A própria McCaul, ao descrever a unidade da SJCV de Antong na Coréia, ressaltava as qualidades dos serviços prestados tanto em nível de higiene como no tratamento aos feridos: "O hospital na sede era perfeito. Todas as precauções foram usadas para prevenir a propagação de doenças infecciosas. Havia pias e caldeiras para esterilizar água. O médico encarregado explicou tudo." 96

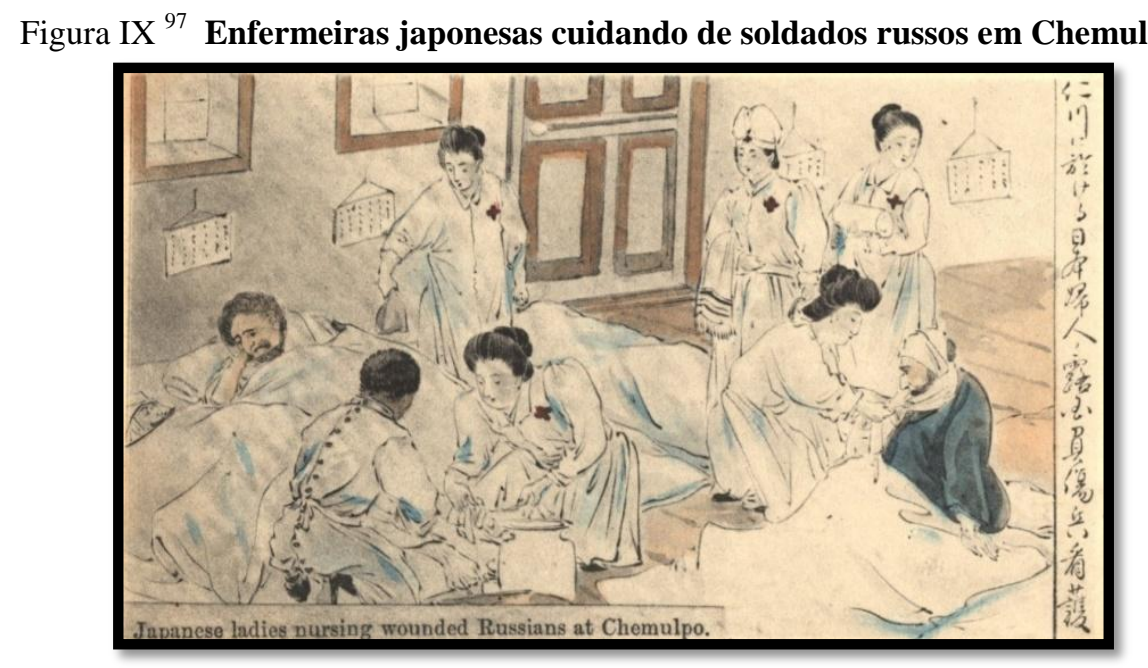

received special pay in addition to normal pay on war-time duty." TAKAHASHI, Aya. The Development of the Japanese Nursing Profession. Op. cit., p. 98.

95 "Red Cross in Tokyo. Work of the Japanese Hospital in the Nation's Capital". New York Times, $07 / 11 / 1904$

96 "Red Cross in Japan. Miss Ethel McCaul's book about Hospitals and Sanitary Arrangements". New York Times, 18/03/1905.

${ }^{97}$ Disponível em: <https://br.pinterest.com/pin/302304193715649644/> Acessado em: 21/03/2018 
Na China, a recém-criada SICVX realizava esforços para prover seus cidadãos, populações locais, soldados e refugiados com importantes serviços de ajuda humanitária. Suas ações deram resultados positivos durante a guerra:

Ao fim da Guerra Russo-Japonesa, em 1905, o novo grupo da Cruz Vermelha havia evacuado mais de 130 mil refugiados da Manchúria e coordenado mais de vinte centros de ajuda humanitária e hospitalar na região, auxiliando mais de um quarto de milhão de pessoas. ${ }^{98}$

\section{A SJCV e a SICVX no Pós-Guerra}

Vitorioso, uma vez mais, o Japão foi elevado ao status de potência e passou a contar com um novo tipo de reconhecimento por parte da comunidade internacional. Tal deveu-se não apenas à demonstração de seu poderio militar como também pela exemplar atuação do Estado e de seus oficiais dentro dos parâmetros do Direito Internacional e do respeito ao Direito Humanitário Internacional..$^{99}$ Respeito esse que, em grande medida, foi demonstrado através da forte e expressiva atuação de sua sociedade nacional da Cruz Vermelha em favor e socorro aos militares feridos, nacionais se estrangeiros, de forma legalmente neutra e imparcial. ${ }^{100}$

A SJCV passou a ser considerada referência nas formas de organização e gerenciamento institucional e a contar com um prestígio internacional. Largamente elogiada, a instituição e suas formas de atuação ganharam espaço e cobertura na imprensa internacional, com ênfase aos Estados Unidos, a Grã-Bretanha e a China. Nas matérias destacava-se a qualidade, sofisticação e humanidade dos tratamentos e dos cuidados dispensados aos feridos e necessitados, a impressionante estrutura a serviço da instituição e sua economia, ${ }^{101}$ além do suporte fornecido pelo Estado e pelo conjunto de seus cidadãos, dentro e fora do país. Tais qualidades e características permitiram-na exercer considerável influência nos círculos humanitários ao redor do globo.

Internamente, a instituição, já consolidada, continuou sua trajetória de crescimento e fortalecimento. Externamente, ela passou a desempenhar papel

\footnotetext{
${ }^{98}$ REEVES, Caroline. "From Red Cross to Golden Arches". Op. cit., p. 122.

99 "How Japan in war time observes International Law". New York Times, 19/06/1904.

${ }^{100}$ KOSUGE, N. Margaret. “The 'non-religious' red cross emblem and Japan”. Op. cit., p. 83.

101 "LONDON, June 13 - Addressing the International Red Cross Conference today Baron Ozawa, Vice President of The Red Cross Society of Japan, said the Japanese Ambulance Corps during the RussoJapanese War had to deal with 622.688 cases. The number they succored in the hostile camps and on hostile ships raised the number to far above a million. This was all done on less than $\$ 2.500 .000$. They had not any women nurses [acting in the hostile camps]. The small cost was due mainly to the strict centralization of the Japanese system." "Japan's Red Cross Cheap". New York Times, 14/06/1907.
} 
importante na propaganda nacional a serviço do Estado e, contando com a participação efetiva da Imperatriz Haruko e seu patrocínio, espraiou seu campo de atuação no estrangeiro como por ocasião do terremoto de São Francisco em $1906{ }^{102}$

Seus médicos e enfermeiras, referências na assistência e socorro aos feridos de guerra, receberam delegações de outras nações e congêneres para observação e treinamento, assim como, a realizar missões no exterior com propósito de promoção de cooperação e intercâmbio de práticas e conhecimentos médicos: ${ }^{103}$ assim as missões a Londres, Paris e Petrogrado (1914-1916), já no contexto da Primeira Guerra Mundial. ${ }^{104}$

Enquanto isso, na China, a SICVX passava por uma fase importante de reestruturação, regulamentação e expansão de suas atividades no pós-guerra. Como bem, expõe Reeves, primeiro ela compor seus quadros incorporando cada vez mais chineses, ao invés de missionários e médicos ocidentais. Com o saldo dos fundos levantados durante a guerra, algo como meio milhão de taéis, foi aberta uma escola de medicina - para a formação de jovens chineses (homens e mulheres) em medicina militar e enfermagem ${ }^{105}$ - e um hospital da Cruz Vermelha, ambos em Xangai. ${ }^{106}$

Com o suporte e patrocínio de autoridades como dos já comentados Yang Ru, Wo Zhongxi, Lu Haihuan e Sheng Xuanhai, as atividades predominantemente médicas e de socorro da sociedade continuaram e expandiram rapidamente o alcance e a sofisticação no cuidado aos seus concidadãos em todo o país durante as situações de conflito ou de desastre. ${ }^{107}$ Por exemplo, a SICVX atuou de maneira decisiva no socorro às vítimas dos sucessivos tumultos no norte da China, além, de fornecer quando necessário auxílio aos esforços humanitários em outros países. Assim como a SJCV, a SICVX também colaborou com os esforços humanitários em São Francisco, 1906. ${ }^{108}$

No campo interno, a instituição passou por um processo de reconhecimento e incorporação, pelo menos no campo formal, à burocracia do Estado Qing. Em 1908, Sociedade Internacional da Cruz Vermelha de Xangai foi diluída e restaurada sob nova designação de Sociedade da Cruz Vermelha Chinesa (中国红字会 Zhōngguó Hóng

\footnotetext{
102 "After the 1906 San Francisco earthquake, the Japanese Red Cross collected \$146,000 for the American relief effort, marking American relief effort, marking the first overseas operation by the Society." Informação retirada da cronologia apresentada na sessão 'História' do site oficial da SJCV. Disponível em: <http://www.jrc.or.jp/english/about/history/>. Acessado em 22/03/2018.

${ }^{103}$ Essas missões tinham também caráter diplomático, servindo a causa da propaganda nacional.

${ }^{104}$ Essas missões ocorreram entre 1914-1916.

${ }^{105}$ LI, Yannan. Red Cross Society in Imperial China, 1904-1912. Op. cit., p. 15.

${ }^{106}$ REEVES, Caroline. "Developing the Humanitarian Image”. Op. cit., p. 122.

${ }^{107}$ LI, Yannan. Red Cross Society in Imperial China, 1904-1912. Op. cit., p. 22.

${ }^{108}$ REEVES, Caroline. "Developing the Humanitarian Image". Op. cit., p. 123.
} 
Shízì Huì). Contando com a estrutura já existente, a organização continuou sediada em Xangai e sob a direção privada de lideranças da elite chinesa até $1910 .{ }^{109}$

Através de edito imperial, a instituição foi colocado sob controle governamental, subordinada ao Ministério da Guerra, e renomeada como Grande Qing Sociedade da Cruz Vermelha (Da Qing Hóng Shízì Huì). ${ }^{110}$ Tal medida, sofreu imediata oposição de Shen Dunhe, fundado e ex-presidente da SICVX, que tentou de todas as formas manter o status privado e independente da instituição. E neste particular, como aponta $\mathrm{Li}$, ele logrou sucesso, pois "nenhuma intervenção governamental substancial foi observada, a sociedade permaneceu independente, e Shen reteve 'o controle gerencial de fato" "111

Esgotado com as guerras revolucionárias que estouraram nesse ano, o governo imperial pouco fez para impedir as manobras de Shen. ${ }^{112}$ No ano seguinte, após uma troca de presidente e uma revisão na nomenclatura, a instituição voltou a se chamar Sociedade da Cruz Vermelha Chinesa (SCVC) e teve seu conselho internacional restaurado. Esse permaneceu até 1912 na condução dos destinos da instituição.

Depois de um processo longo de adequação da instituição às normas estabelecidas pelo CICV e com o apoio da Imperatriz Haruko do Japão, a SCVC foi oficialmente reconhecida e passou a ser um membro de plenos direitos no movimento da Cruz Vermelha. ${ }^{113}$ Apesar das turbulências que ainda se seguiriam durante a fase republicana, a instituição continuou seu percurso "trabalhando com os governos conforme surgiram e trabalhando apesar deles quando caíram." 114

\section{Referências bibliográficas}

CHEVRIER, Yves. Mao e a Revolução Chinesa. Século XX. São Paulo: Ática, 1996. COURSIER, Henri. La Croix-Rouge Internationale. Paris : PUF, 1959.

DAVIS, Mike. Holocaustos Coloniais: clima, fome e imperialismo na formação do Terceiro Mundo. Rio de Janeiro: Record, 2002.

DOWER, John W. "Throwing Off Asia I". Visualizing Cultures, Massachusetts Institute of Technology,2008,p.16. Disponível em: 〈http://visualizingcultures.mit.edu>. Acessado em: 16/02/2018.

DOWER, John W. "Throwing Off Asia II". Visualizing Cultures, Massachusetts Institute of Technology, 2008.Disponívelem: http://visualizingcultures.mit.edu. Acessado em: 16/02/2018.

\footnotetext{
${ }^{109}$ LI, Yannan. Red Cross Society in Imperial China, 1904-1912. Op. cit., p. 15 - 16.

${ }^{110}$ Idem., p. 16.

111 Ibidem.

112 "One explanation was at the time the Qing government was so swamped in the Revolutionary War that it did not have the energy or resource to deal with Shen's 'rebellion"'. Ibidem.

${ }^{113}$ REEVES, Caroline. "Developing the Humanitarian Image". Op. cit., p. 123.

${ }^{114}$ Idem., p. 122.
} 
EDGERTON-TARPLEY, Katheryn. "'Pictures to Draw Tears from Iron' The North China famine of 1876-1879. In: Visualizing Cultures, Massachusetts Institute of Technology, 2010. Disponível em: 〈http://visualizingcultures.mit.edu〉. Acessado em: 16/02/2018

FAIRBANK, John. K. The United States and China. Harvard University Press. 1983.

FAIRBANK, John. K.; REISCHAUER, Edwin O.; CRAIG, Albert M. East Asia: Tradition and Transformation. Boston: Houghton Mifflin Company, 1989.

KÄSER, Frank. "A civilized nation: Japan and the Red Cross 1877-1900." In: European Review of History: Revue européenne d'histoire. 2016, 23:1-2, pp. 16-32.

KOSUGE, N. Margaret. "The 'non-religious' red cross emblem and Japan”. In: RICR Mars IRRC March. 2003, vol. 85, n.849, pp. 75-93.

LI, YANNAN. Red Cross Society in Imperial China, 1904-1912. The Center on Philanthropy at Indiana University.

MOTTA, Bruno Pontes. "Destruir a Casa de Ferro": o escritor Lu Xun na China do Quatro de Maio, 1918-1927. UFPE Monografia de Bacharelado em História. UFPE, 2018.

REEVES, Caroline. "Developing the Humanitarian Image in the Late Nineteenth and Early Twenteenth-Century China.” Humanitarian Photography: a History. Cambridge University Press, 2015.

REEVES, Caroline. "From Red Cross to Golden Arches: China, The Red Cross, and the Hague Peace Conference, 1899-1900". BENTLEY, Jerry H.; Bridenthal, Renate; YANG, Anand A. Interections. Transregional Perspectives on World History. Honolulu: University of Hawai'i Press, 2005.

RUFIN, Jean-Christophe. L'aventure humanitaire. Paris : Gallimard, 1994.

SANTIAGO, Hugo Leonardo A. Os Campos da Fome: Estudo sobre a Gestão da Seca no Mundo Rural pelo Estado Chinês entre 1876 e 1879. UFPE. TCC História, 2017.

SANTOS, Renata C. Nobrega; DABAT, Christine. "A Civilização Acompanha as Locomotivas': A implementação da rede ferroviária no Brasil e na China, 1852-1912". Revista Leste Vermelho - de estudos críticos asiáticos. Vol. 3 - n. 1, 2017, pp. 453-509.

SPENCE, Jonathan D. Em Busca da China Moderna: quatro séculos de História. São Paulo: Companhia das Letras, 1995.

TAKAHASHI, Aya. The Development of the Japanese Nursing Profession: Adopting and Adapting. New York: Routledge Curzon, 2004.

ZIERER, Otto. Pequena história das grandes nações: Japão. São Paulo: Círulo do Livro S. A., 1976.

"The Japanese Eruption - Graphic Details. Villages Buried and Hundreds of Lives Lost." New York Times, 07/09/1888.

“How Japan in war time observes International Law". New York Times, 19/06/1904.

"New York Japanese discuss war found". New York Times, 13/02/1904.

"Japanese Jubilant Here". New York Times, 10/02/1904.

"Red Cross in Tokyo. Work of the Japanese Hospital in the Nation's Capital". New York Times, 7/11/1904.

"Red Cross in Japan. Miss Ethel McCaul's book about Hospitals and Sanitary Arrengements". New York Times, 18/03/1905.

“Japan's Red Cross Cheap”. New York Times, 14/06/1907. 